\title{
Ruthenium Nanoparticles for Catalytic Water Splitting
}

Jordi Creus ${ }^{+},{ }^{[a, b, c]}$ Jonathan De Tovar ${ }^{+},{ }^{[a]}$ Nuria Romero, ${ }^{[a]}$ Jordi García-Antón, ${ }^{[a]}$ Karine Philippot ${ }^{\star},[b, c]$ Roger Bofill, ${ }^{*}$ [a] and Xavier Sala ${ }^{*}$, [a]

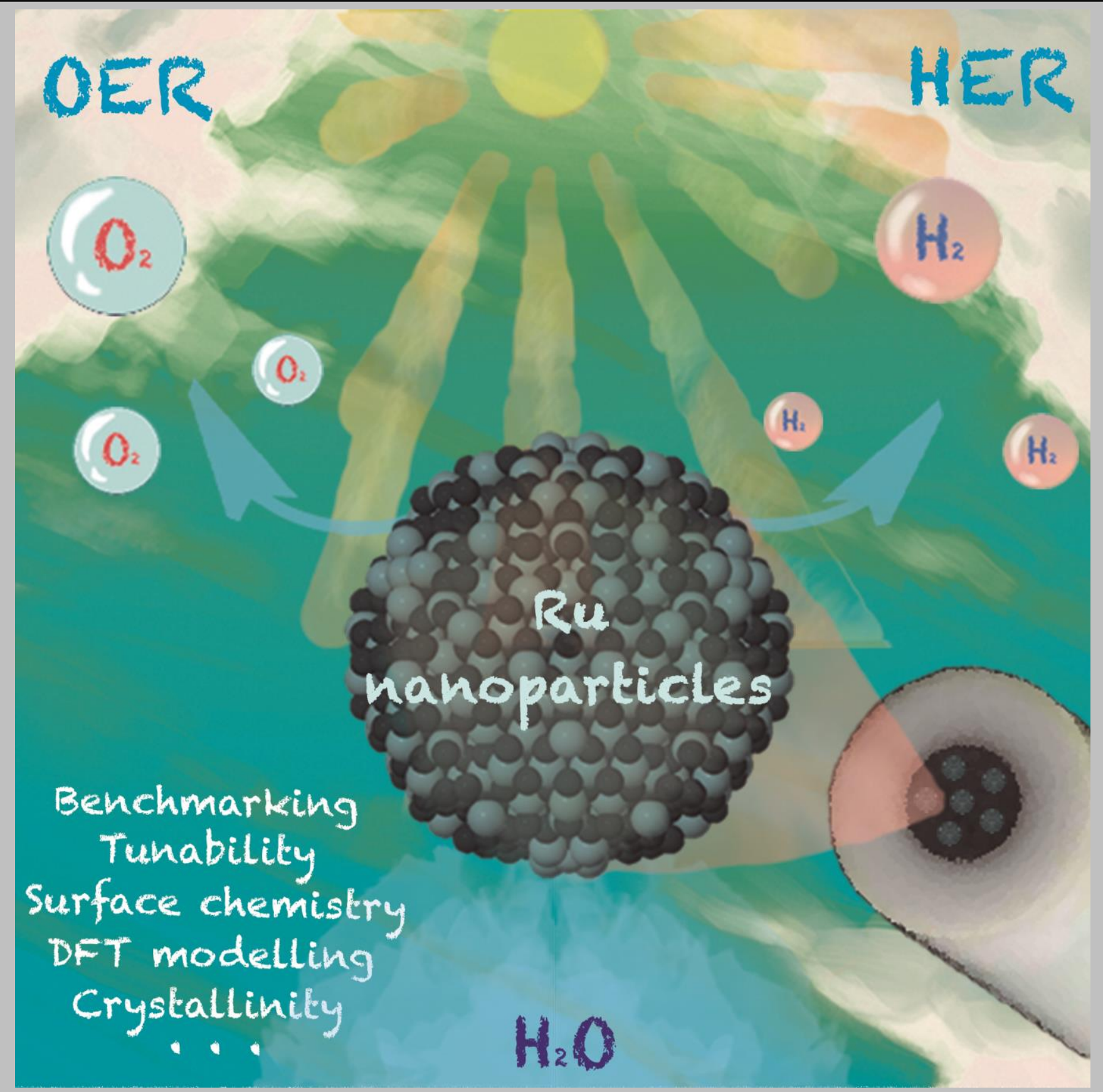


Abstract: Both global warming and the limited fossil resources make the transition from fossil to solar fuels an urgent matter. In this regard, the splitting of water activated by sunlight is a sustainable and carbon-free new energy conversion scheme able to produce efficient technological devices. Having at disposal appropriate catalysts is essential for the proper kinetics of the two key processes involved, namely the oxygen evolution reaction (OER) and the hydrogen evolution reaction (HER). During the last decade nanoparticulated $\mathrm{Ru}$ derivatives have emerged as true potential substitutes for the state-of-the art $\mathrm{Pt}$ and IrOx species for HER and OER, respectively. Thus, after a first section summarizing the most common methods for catalyst benchmarking, this review covers the most significant developments on Ru-based nanoparticles used as catalysts for the water splitting process. Furthermore, the key factors that govern the catalytic performance of these nanocatalysts are discussed in view of future research directions.

\section{Introduction}

High consumption of fossil fuels together with the accumulation of $\mathrm{CO}_{2}$ in the atmosphere due to their combustion have put forward the urgent need for a cheap, clean and carbon-neutral energy source. One of the most attractive and possible solutions to face this challenge is the production of $\mathrm{H}_{2}$ by the splitting of water (WS, Eq. 1) photo-activated by sunlight. This method to produce $\mathrm{H}_{2}$ mimics what green plants, algae and cyanobacteria do to store sunlight energy in chemical bonds, and is one of the processes known as artificial photosynthesis. [1] In this redox process, water is oxidized to molecular oxygen at the anode (Eq. $2 \mathrm{a}$ and $2 \mathrm{~b}$ at neutral/acidic and basic $\mathrm{pH}$, respectively) and the released electrons and protons produce molecular hydrogen at the cathode (Eq. $3 a$ and $3 b$ at neutral/acidic and basic $\mathrm{pH}$, respectively).

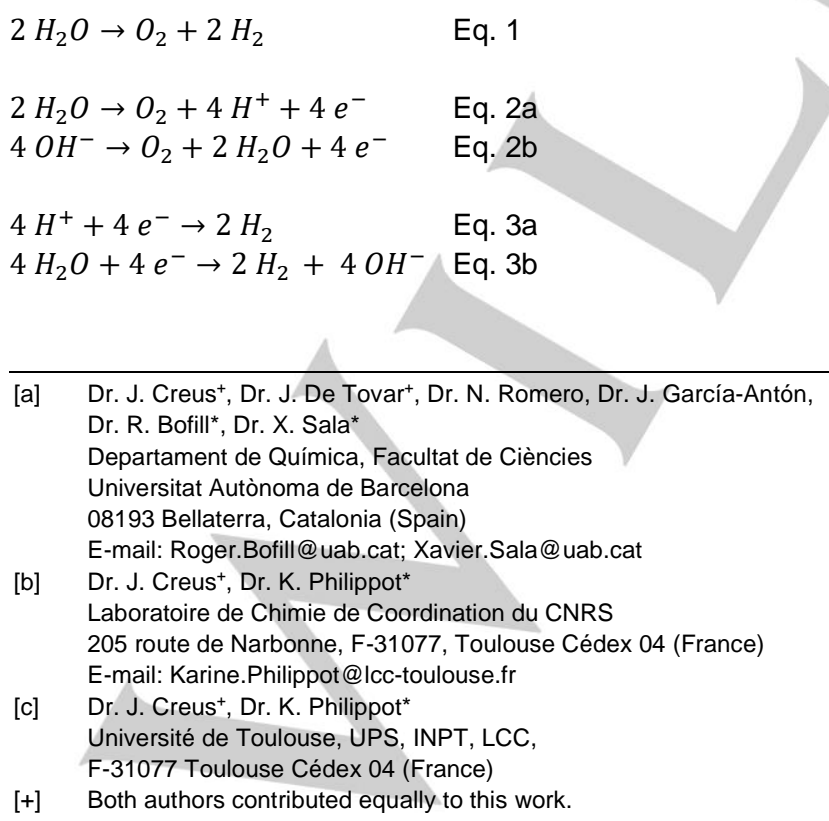

[a] Dr. J. Creus ${ }^{+}$, Dr. J. De Tovar ${ }^{+}$, Dr. N. Romero, Dr. J. García-Antón, Dr. R. Bofill ${ }^{*}$, Dr. X. Sala*

Departament de Química, Facultat de Ciències Universitat Autònoma de Barcelona 08193 Bellaterra, Catalonia (Spain) E-mail: Roger.Bofill@uab.cat; Xavier.Sala@uab.cat

[b] Dr. J. Creus ${ }^{+}$, Dr. K. Philippot* Laboratoire de Chimie de Coordination du CNRS 205 route de Narbonne, F-31077, Toulouse Cédex 04 (France) E-mail: Karine.Philippot@Icc-toulouse.fr

[c] Dr. J. Creus ${ }^{+}$, Dr. K. Philippot* Université de Toulouse, UPS, INPT, LCC, F-31077 Toulouse Cédex 04 (France)

[+] Both authors contributed equally to this work.

These processes are kinetically slow because of their mechanistic complexity -especially for the oxidation half reaction- and the difficulty of evolving gases from a liquid phase, and therefore it is of upmost importance to find proper catalytic systems able to accelerate them. In this context, nanoparticles (NPs) are highly interesting chemical systems owing to their unusual properties at the interface of those of molecular species and bulk counterparts. ${ }^{[2]} \mathrm{NPs}$, if properly characterized, ${ }^{[3]}$ are of particular interest for applications in catalysis given their high specific surface area and the possibility of depositing/embedding them in various supports and also to surface-functionalize them through diverse strategies. This offers great opportunities in terms of reusability, for example in electrocatalytic processes in which they can act as the active supported species onto solid electrodes.

Concerning the oxygen evolution reaction (OER, Eq. 2a/2b), anodes made with iridium oxide $\left(\mathrm{IrO}_{\mathrm{x}}\right)$ have been historically used to perform this first half-reaction of the water splitting process, since this material shows excellent electrocatalytic performance under the harsh conditions required. ${ }^{[4]}$ However, significant activity of heterogeneous $\mathrm{RuO}_{2}$ in the OER has also been known for 30 years, ${ }^{[5,6]}$ which is attributed to the average binding energy of the surface bonded oxygen species. ${ }^{[7]}$ In fact, several interesting features make $\mathrm{RuO}_{2}$ particularly promising to replace the highly active state-of-the-art $\mathrm{IO}_{x}$ species, which are expensive and scarce, in proton exchange membrane (PEM) electrolyzers for WS. Contrarily to traditional water electrolyzers that operate in basic media, PEM WS systems work under acidic conditions and provide numerous performance advantages that make them ideal devices for the delocalized storage of renewable electricity at a small scale. ${ }^{[8]}$ Given that active and stable $1^{\text {st }}$ row transition metal-based oxide catalysts for the OER in acidic media are elusive, $\mathrm{RuO}_{2}$ turns out to be a remarkable candidate for PEM systems, especially if taking into account that $\mathrm{Ru}$ is at least six times cheaper than Ir. However, for $\mathrm{RuO}_{2}$ to be employed for practical applications, maximizing the number of active sites at its surface is of paramount importance in order to increase its efficiency. Therefore, nanoparticulated systems, with large surface area to volume ratios, present obvious advantages and are particularly desirable.

Today most of the mechanistic knowledge available on the OER comes from the research performed for the last 40 years on $\mathrm{Ru}$ molecular complexes. [9] Cycling even at the millisecond timescale, ${ }^{[10]} \mathrm{Ru}$ complexes have proven to be highly active electrocatalysts for the OER, showing remarkable stability if properly designed. [ ${ }^{11}$ ] But the reaction rates of their heterogeneous counterparts, namely $\mathrm{RuO}_{2}$, are typically several orders of magnitude lower, even when nanoparticulated materials are employed; turnover frequency (TOF) values are below $1 \mathrm{~s}^{-1}$ (see Section 3 below), that highly contrasts to TOFs in the $10000 \mathrm{~s}^{-1}$ range for the best $\mathrm{Ru}$ molecular OER catalysts. ${ }^{[10]}$ However, a drawback frequently threatens the catalytic performance of Ru molecular water oxidation catalysts (WOCs): they can be vulnerable under the highly oxidizing conditions used and show a tendency towards ligand oxidation/substitution and thus metal oxide formation, among 
other processes. ${ }^{[11]}$ Interestingly, the in situ formation of $\mathrm{RuO}_{2}$ from the decomposition of grafted $\mathrm{Ru}$ molecular complexes under catalytic turnover conditions has recently led to both dramatically increased activities and stabilities. [12 ] Thus, unraveling the factors ruling the performance of $\mathrm{RuO}_{2}$ OER catalysts, namely under the form of NPs, is of upmost relevance. The attention of the scientific community towards this subject has increased in recent years.

The second half-reaction of water splitting, the hydrogen evolution reaction (HER, Eq. 3a), is mechanistically simpler than the OER at acidic/neutral pH (Eq. 2a). Compared to the oxidative process where four $\mathrm{H}-\mathrm{O}$ bonds have to be broken and an $\mathrm{O}=\mathrm{O}$ double bond formed while releasing 4 electrons and 4 protons, the HER involves only the formation of one $\mathrm{H}-\mathrm{H}$ bond by the reduction of two $\mathrm{H}^{+}$groups. This divergence is evidenced with the onset overpotential $\left(\eta_{0}\right)$-the difference between the thermodynamic equilibrium potential and the actual potential where the catalytic reaction starts- that heterogeneous catalysts require for each half-reaction, in general being $<100 \mathrm{mV}$ for HER electrocatalysts and $>200 \mathrm{mV}$ for OER electrocatalysts (Tables 1-4).

In the solid phase, Pt has been the most used metal for the HER, being the most active metal in reducing protons, especially at acidic $\mathrm{pH}$ values. In these conditions, the $\mathrm{M}-\mathrm{H}$ bond energy plays a key role in proton reduction catalysis given that a high $\mathrm{M}-\mathrm{H}$ binding energy eases the adsorption of protons (but hardens the $\mathrm{H}_{2}$ desorption), whereas a low $\mathrm{M}-\mathrm{H}$ binding energy has an opposite effect. Platinum is located at the centre of the so-called volcano plot for proton reduction catalysts because it possesses the optimum $\mathrm{M}-\mathrm{H}$ binding energy, which is neither too low nor too high. ${ }^{[13,14]}$ Ruthenium presents a $\mathrm{M}-\mathrm{H}$ bond only slightly weaker compared to $\mathrm{Pt}$, which hardly decreases the HER catalytic efficiency, both according to experimental results and DFT calculations. ${ }^{[15]}$ Furthermore, Ru has been shown to be stable both under acidic and basic conditions which provides this metal an extreme versatility in terms of working conditions, in contrast to $\mathrm{Pt}$, whose long-term stability at basic $\mathrm{pH}$ is not optimal. ${ }^{[16]}$ Additionally, the cost of $\mathrm{Ru}$ is noticeably lower -at least six times- than that of Pt. These characteristics all together have boosted the re-birth of Ru metal as a HER electrocatalyst in the last five years, particularly when it is in the form of NPs. This review focuses on the most remarkable Ru-based NP systems reported as HER/OER (electro)catalysts for the water splitting process and highlights the key factors that rule the catalytic performance of these nanomaterials. Given the crucial role of benchmarking for the objective assessment of the reported systems, a forefront section dedicated to this end has been included. Finally, future research directions are also discussed.

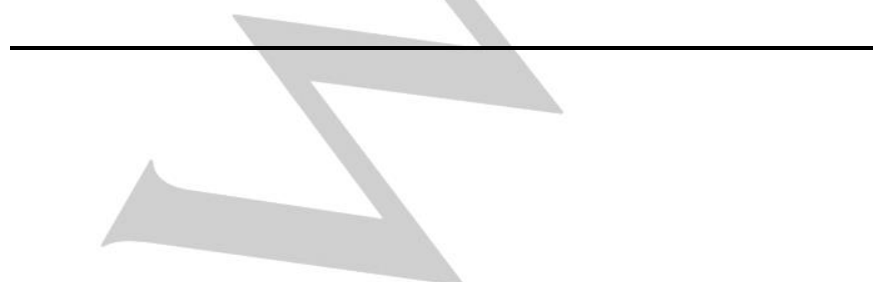

Dr. Jordi Creus graduated in Chemistry at the Universitat Autònoma de Barcelona (UAB) and obtained an M. Sc. Diploma in "Synthesis, catalysis and molecular design" in 2014 by the Rovira i Virgili University (URV) and the Catalan Institute of Chemical Research (ICIQ) in Tarragona. In 2018 he completed his $\mathrm{PhD}$ in Chemistry in an international joint supervision between the $\mathrm{UAB}$ and the Laboratoire de Chimie de Coordination (LCC-CNRS) at the Paul Sabatier University (UPS) in Toulouse.

Dr. Jonathan De Tovar obtained his $\mathrm{PhD}$ in $\mathrm{Pd}$ and Co-based (nano)catalysts for $\mathrm{C}-\mathrm{C}$ coupling and artificial photosynthesis from the Universitat Autònoma de Barcelona (UAB) in 2018. By the beginning of 2019 , he joined Prof. Laurent Djakovitch group at the Institut de recherches sur la catalyse et l'environnement de Lyon (IRCELYON) as postdoctoral researcher, where he works on the development of hyperactive catalytic species in the liquid phase from molecular or colloidal systems.

Dr. Nuria Romero, born in Toledo (Spain), is a postdoctoral fellow and teacher at the Universitat Autònoma of Barcelona (Spain). She graduated from Chemistry at the Universidad de Castilla-La Mancha (Spain) in 2011. She concluded the $\mathrm{PhD}$ in organometallic chemistry at the Laboratoire de Chimie de Coordination of Toulouse (France) in 2014. Then she did an 18 months postdoctoral stay for the development of new catalysts for olefin polymerization at the Université de Rennes 1 (France), in collaboration with Total Raffinage Chimie in Feluy (Belgium). Since 2016 she has focused in the development of new catalysts and nanocatalysts for the water splitting reaction.

Dr. Jordi García-Antón was born in Cubelles (Barcelona, Spain) in 1976. He received his $\mathrm{PhD}$ in Chemistry in 2003 from the Universitat Autònoma de Barcelona (UAB). After a postdoctoral stay at the Laboratoire de Chimie de Coordination in Toulouse (France) in the group of Dr. Bruno Chaudret, he joined the UAB as a lecturer in chemistry. His research interest is focused on coordination chemistry on the surface of metallic nanoparticles and artificial photosynthesis.
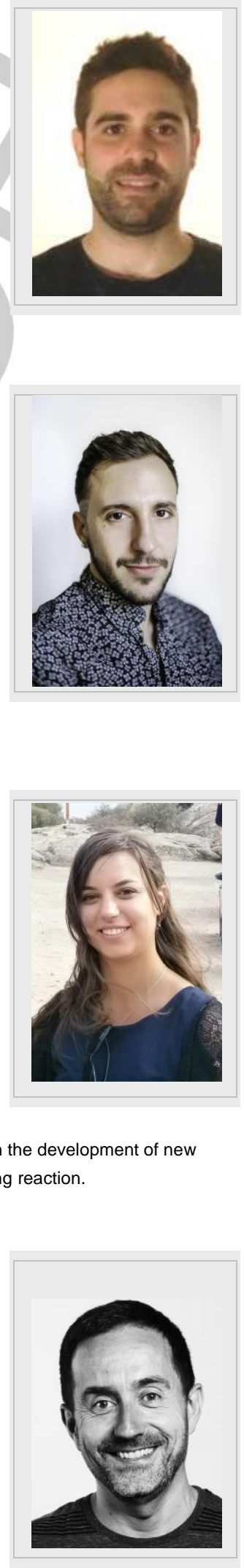
Dr. Karine Philippot. After a PhD in Chemistry at the University of Toulouse and a postdoctoral position at Catalysis Department of Rhodia-Lyon, Karine Philippot integrated the CNRS Laboratory of Coordination Chemistry in Toulouse (France) where she is Senior Researcher and the head of team "Engineering of Metal Nanoparticles". Her research concerns metal nanoparticles and composite nanomaterials synthesis by using molecular chemistry concepts. The domains of application are colloidal and supported catalysis as well as energy. She is co-author

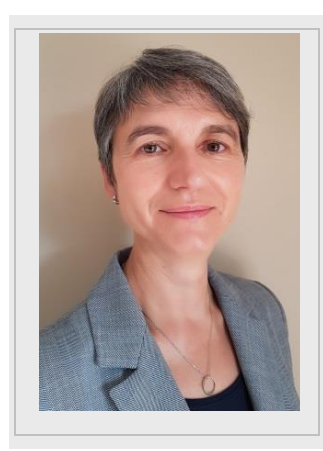
of $>170$ peer reviewed papers (including 5 reviews, 13 proceedings, 9 book chapters, 6 patents) and co-editor of the book "Nanomaterials in Catalysis" (Wiley).

Dr. Roger Bofill obtained the PhD in Chemistry at the Universitat Autònoma de Barcelona (UAB) in 2001. After a postdoctoral stay in Prof. M.S. Searle group at the Centre for Biomolecular Sciences, University of Nottingham (UK), he rejoined the UAB as a lecturer and researcher in 2004, obtaining his tenure in 2009. His recent research interests have focused on the use of chemistry as a tool for understanding the complexity of our biological world and obtaining a source of sustainable energy.

Dr. Xavier Sala obtained his PhD in Chemistry from the University of Girona (UdG) in 2007. After postdoctoral research with P. W. N. M. van Leeuwen and A. Llobet at ICIQ, he is currently Associate Professor of Chemistry at the Universitat Autònoma de Barcelona (UAB) where he leads the Selective Oxidation Catalysis (SelOxCat) research group. His research interest focuses on the study, comprehension and development of the key reactions involved in the production of renewable fuels through redox catalysis.

\section{General methodology and activity benchmarking}

The majority of Ru-based NP systems described as HER/OER catalysts have been evaluated electrochemically after deposition onto the surface of conducting electrodes, with glassy carbon (GC) electrodes being the most common example. However, the use of pressed Pt powder discs as alternative to oxidizable Cbased electrodes has also been reported for OER applications. ${ }^{[17,18]}$ Since in both HER and OER gases are continuously evolving, the use of glassy carbon rotating disk electrodes (RDE-GC) is highly recommended. The disk rotation results in a laminar flow of solution towards and across the electrode that controls the steady-state current in spite of diffusion. At the same time this minimizes the $\mathrm{H}_{2}$ or $\mathrm{O}_{2}$ gas accumulation at the electrode surface, thus ensuring a better accessibility of the catalyst active sites under turnover conditions and also a more real quantification of evolved gas when analyzed with specific probes.

Meaningful comparison of the performance and stability of electrocatalytic materials prepared for the WS reactions presents inherent difficulties arising from the wide set of conditions (varied supports and catalyst loadings, diverse electrolytes and $\mathrm{pH}$ ranges,...) employed to test their performance. Traditionally, the electrochemical activity of heterogeneous catalysts has been normalized by the total amount of catalyst or metal present, thus yielding the so-called mass activity parameter (generally expressed as A. $\mathrm{mg}^{-1}$ or $\mathrm{A} \cdot \mathrm{g}$ 1). ${ }^{\left[8^{19]}\right.}$ However, this represents an average activity that does not take into account the putative presence of different sites in the sample (e.g. exposed/active sites vs. unexposed/inactive sites). Thus, several authors have proposed several methodologies for normalizing the vast electrochemical data available for both HER and OER catalysis. $[4,16,19,20,21,22,23]$ Therefore, a set of benchmarking parameters are nowadays used to assess the intrinsic activity and stability of the systems in a relatively fast and easy/affordable manner. An overview of the parameters typically defined to this purpose and the most frequently related methodologies can be found hereafter.

The first relevant figure of merit is the overpotential at the beginning of the catalytic process, $\eta_{0}$, which can be distinguished by a change on the current intensity ( $I$ ) due to a Faradaic process when performing voltammetric measurements. Accurately determining a slope change in a voltammetric experiment is not always straightforward and thus $\eta_{0}$ determination is typically not absent of subjectivity. Thus, the overpotential required to achieve a current density $(|j|)$ of 10 $\mathrm{mA} \cdot \mathrm{cm}^{-2}\left(\eta_{10}\right)$, which is approximately the current density expected for a solar water-splitting device subjected to 1 sun illumination and working at a solar-to-fuel efficiency of $10 \%$, has arisen as a commonly accepted benchmarking parameter for both HER and OER. In addition, in order to assess the stability of the studied catalysts, $\eta_{10}$ can be compared at the beginning and after continuous catalytic turnover. Typical reaction times of $2 \mathrm{~h}$ are applied for short-term and more than $12 \mathrm{~h}$ for long-term stability tests, as proposed by Jaramillo et al. ${ }^{[16]}$ It is noteworthy that long-term ( $>12 \mathrm{~h}$ ) stability tests are not frequently reported. If the chosen benchmarking parameter is $\eta_{10}$, determining the active surface area of the tested electrocatalyst is of paramount importance in order to assess its activity. Note that $\eta_{10}$ can also be (and is widely) measured by normalizing the obtained current intensities by the total geometric area of the employed electrode instead of that of the electrocatalyst. However, this methodology provides scarce information about the intrinsic activity of the catalyst, being of relatively low interest as a tool of objective benchmarking. Specific surface areas are commonly determined either by the so-called Brunauer-Emmett-Teller (BET) method, 
which is based on gas adsorption measurements, or through electrochemical measurements. In general, BET is a welldefined empirical measurement leading to relatively accurate values of the total specific surface of the analyzed electrocatalyst. But given that not all surface sites are usually active, overestimation of the catalytically active surface area is common with this method, which leads to the underestimation of the intrinsic activity of the real active sites. ${ }^{[20]}$ The electrochemical method to assess electrocatalyst surface areas relies on the determination of the electrochemically active surface area (ECSA). To determine the ECSA, it is necessary to measure the double-layer capacitance $\left(\mathrm{C}_{\mathrm{DL}}\right)$ of the material, which can be assessed through two different methods. The first one, proposed by Jaramillo et al., consists in the measurement of CVs at different scan rates in non-faradaic regions. $[4,16,20]$ The second one is based on electrochemical impedance spectroscopy (EIS) measurements in the same non-faradaic regions. Although in general the $C_{D L}$ measured by both methods tend to agree within $\pm 15 \%$, some authors claim that the latter may be preferable. ${ }^{[19]}$ From the ECSA values, the so-called roughness factor (RF) can be measured as $\mathrm{RF}=$ $\mathrm{ECSA} /$ geometrical electrode area. If the current density $|j|$ is normalized by the RF, the so-called specific activity $(|j s|=|j| / R F)$ can be obtained. It allows comparing the performance of very diverse systems with different catalyst loadings and electrode areas. Nevertheless, even if in principle the ECSA method is more realistic in terms of describing active surface sites, it shows important experimental difficulties that make it inaccurate, thus potentially leading either to the underestimation or overestimation of the true catalytically active area. ${ }^{[20]}$ ECSA and BET were recently compared by Jaramillo and co-workers as methods for normalizing the activity of OER nanoparticulate electrocatalysts. ${ }^{[20]}$ However, it remains unclear which should be the method of choice since it strongly depends on the type of solid to be studied. Thus, reporting specific activities per duplicate through both ECSA and BET seems a desirable practice to get higher confident results.

The determination of the turnover number (TON) and turnover frequency (TOF) per real catalytic active site is another significant benchmarking parameter to be discussed. Normally, the total number of active sites present in a metal-based catalyst deposited onto the surface of a conductive electrode can be directly determined by integrating the area below the CV oxidation or reduction peak according to Faraday's law, as is the case for $\mathrm{Ni}$ and Co-based nanocatalysts. ${ }^{[19]}$ However, for the particular case of Ru-based NPs no redox processes are commonly observed except from the catalytic current. An alternative method can be used to determine the total number of metallic Ru active sites (which is also valid for metallic Pt). It is the so-called $\mathrm{Cu}$ Under-Potential Deposition method (UPD, Figure 1), in which all metallic $\mathrm{Ru}$ (or Pt) active sites are initially saturated with $\mathrm{Cu}$ atoms by selective $\mathrm{Cu}^{2+}$ electro-reduction (Figure 1a-b). Then, after a controlled oxidation (Figure 1c), deposited $\mathrm{Cu}$ atoms are released into the solution. Copper atoms can be quantified by the integration of the $\mathrm{Cu}$ oxidation wave area (Figure 1d), thus allowing to estimate the number of accessible metallic $\mathrm{Ru}$ (or $\mathrm{Pt}$ ) active sites in the original system. ${ }^{[22,24]}$ Once the total number of active sites present is known, the total amount of $\mathrm{H}_{2}$ or $\mathrm{O}_{2}$ gas molecules detected by a selective probe or the amount of evolved gas per time lapse can be normalized by the total quantity of active sites, thus leading to the TON and TOF values per real active site, respectively. The UPD method is particularly relevant for the benchmarking of HER electrocatalysts (see Section 4 below) where metallic $R u$ sites are the most common catalytically active species.

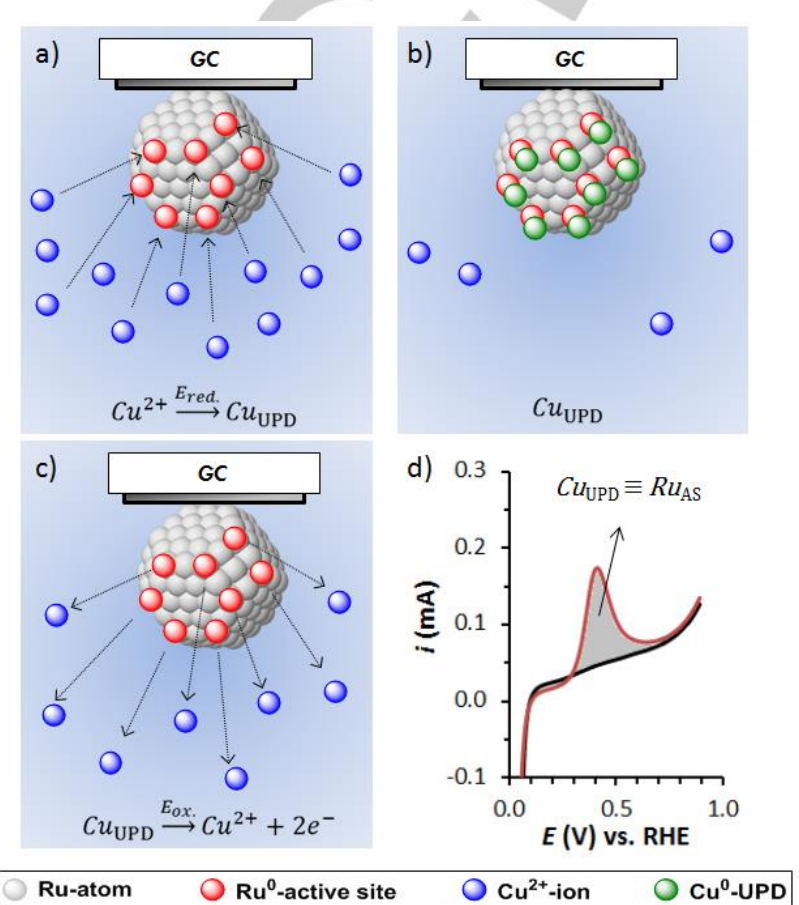

Figure 1. Schematic representation of the $\mathrm{Cu}$ Underpotential Deposition (UPD) method for the determination of catalytic metallic Ru active sites in $\mathrm{Ru}$ based NPs.

Electrochemical Tafel plots, which are defined as the plot of log $|j|$ vs. $\eta$, constitute useful graphical tools for comparing the performance of electrocatalytic materials studied under analogous conditions and thus are suitable for benchmarking purposes. $[25,26]$ Tafel plots can be extracted either from voltammograms, chronoamperometries/chronopotentiometries or from EIS measurements. The Tafel plot slope, expressed as $\mathrm{mV} \cdot \mathrm{dec}^{-1}$, gives information about the kinetics of the electrochemical process. Furthermore, in the particular case of HER, Tafel plots help inferring details on the mechanistic pathway of the catalytic act and, beyond, to classify the catalysts. ${ }^{[19]}$ Thus, heterogeneous HER has been described to occur through two different reaction pathways, namely VolmerHeyrovsky or Volmer-Tafel (Eqs. $4 \& 5$ and 4\&6, respectively):[25,27]

Volmer: $\operatorname{Cat}_{(s)}+H_{(a q)}^{+}+e^{-} \rightarrow \mathrm{Cat}-H_{(a d)}$ Eq. 4 Heyrovsky:Cat $-H_{(a d)}+H_{(a q)}^{+}+e^{-} \rightarrow H_{2(s)}+$ Cat $_{(s)} \quad$ Eq. 5 
Tafel:

$$
2 \mathrm{Cat}-H_{(a d)} \rightarrow H_{2(s)}+2 \mathrm{Cat}_{(s)}
$$

The Volmer step (Eq. 4) is the adsorption of one proton onto the catalyst surface, and is common for all HER electrocatalysts. It is considered as a Proton Coupled Electron Transfer (PCET) step at the surface of the catalyst, and is alternatively called discharge reaction. The desorption step can either go through the electrodesorption of the adsorbed hydrogen atom with a $\mathrm{H}^{+}$ in solution (Heyrovsky step, Eq. 5), which is also a PCET process, or through the recombination of two metal-hydride groups $(\mathrm{M}-\mathrm{H})$ from a unique nanoparticle or from two different ones (Tafel step, Eq. 6).

Thermodynamically, electrocatalysts are ruled by the Nernst equation, which allows to calculate the thermodynamic potentials as $E^{0}\left(\mathrm{H}^{+} / \mathrm{H}_{2}\right)=0.00-0.05916 \cdot \mathrm{pH}$. However, an overpotential $(\eta)$ is always present, and the whole HER kinetics follow the Butler-Volmer equation ${ }^{[28]}$ (Eq. 7),

$|j|=\left|j_{0}\right|\left[-e^{-\frac{\alpha n F \eta}{R T}}+e^{(1-\alpha) \frac{n F \eta}{R T}}\right]$

Eq. 7

where $|j|$ is the current density, $\left|j_{0}\right|$ is the exchange current density, i.e., the residual current of the catalytic system under non-faradaic conditions, $\alpha$ is the charge transfer coefficient, $n$ is the number of electrons transferred, $F$ is the Faraday constant, $R$ is the ideal gas constant and $T$ is the temperature. If $\eta>>$ $\mathrm{RT} / \mathrm{F}$, a linear relationship appears between $\eta$ and $\log (|j|)$ (Eqs. 8 and 9).

$\eta=a+b \cdot \log (|j|)=-\left(\frac{2.3 R T}{\alpha n F}\right) \log \left(\left|j_{0}\right|\right)+\left(\frac{2.3 R T}{\alpha n F}\right) \cdot \log (|j|)$ Eq. 8

$b=\frac{2.3 R T}{\alpha n F} \quad$ Eq. 9

The slope (b, Eq. 9) of the Tafel plot (Eq. 8) gives kinetic information on the rate determining step (rds) among the different reaction pathways. In the case of HER, the rds depends on the binding energy of the $\mathrm{M}-\mathrm{H}$ bond. Thus, if the rds of the reaction is the Volmer step, a typical Tafel slope of $\approx 120$ $\mathrm{mV} \cdot \mathrm{dec}^{-1}$ is obtained. However, if the rds is the Heyrovsky or the Tafel step, characteristic slopes of $\approx 40 \mathrm{mV} \cdot \mathrm{dec}^{-1}$ or $\approx 30$ $\mathrm{mV} \cdot \mathrm{dec}^{-1}$ are observed, respectively.

In the case of OER, its higher mechanistic complexity makes the interpretation of Tafel plots more difficult. From a theoretical point of view, $b$ can change from $120 \mathrm{mV} \cdot \mathrm{dec}^{-1}$ to 30 and even $21 \mathrm{mV} \cdot \mathrm{dec}^{-1}$ depending on the rds and the applied potential (the slope increases with increasing potentials). ${ }^{[25]}$ Furthermore, apart from theoretical complications, important experimental drawbacks have been also reported. ${ }^{[23]}$ First, the dependence of the Tafel slope with the manner in which a metal oxide has been prepared (e.g. the surface roughness) and the history of the electrode. Second, two distinct linear regions with different slopes can be recorded depending on the applied potential, which can be either due to a change of the rds within a given pathway or due to the influence of changing potential on the adsorption of reaction intermediates. And third, an increase of the slope with applied potential may not necessarily be mechanistically relevant but instead due to a reduction in the effective electrode surface area with increasing gas evolution at higher potentials. Altogether these may be the reasons why very rarely mechanistic conclusions are extracted from Tafel plot analysis of OER catalysts.

Finally, the selectivity of the catalysts is commonly measured through the Faradaic efficiency determination in a bulk electrolysis experiment. It corresponds to the percentage of the total amount of electrons that have circulated through the electrochemical system and were effectively used for evolving gas, according to Faraday's law. Also, when rotating ring disk electrodes (RRDE) are employed, the Faradaic efficiency of a HER/OER process can be directly determined from electrochemical measurements, without need of using selective gas detection probes. ${ }^{[19]}$

The benchmarking parameters that have been described here above will be used when available in the following sections of this review in order to compare the catalytic properties of $\mathrm{Ru}$ based nanomaterials both for OER and HER.

\section{Oxygen Evolution Reaction}

$\mathrm{RuO}_{2}$ NPs reported as catalysts for the OER have been prepared by diverse synthetic methodologies that exploit the rich redox chemistry of $\mathrm{Ru}$. As main preparation methods one can cite (hydro)thermal, ${ }^{[29,30,31,32,33]}$ and plasma-assisted ${ }^{[34,35]}$ methods starting both from $\mathrm{RuCl}_{3}$, decomposition of molecular precursors under oxidative (usually electrocatalytic) conditions ${ }^{[12]}$ magnetron sputtering, ${ }^{[8]}$ thermal|[36,37,38,39,40]/ air ${ }^{[41] /}$ electrochemical ${ }^{[31]}$ oxidation of pre-formed metallic Ru NPs, and chemical $^{\left[{ }^{[42]}\right.}$ electrochemical[ ${ }^{[43]}$ or photochemical ${ }^{[44]}$ reduction of $\mathrm{RuO}_{4}^{-}$species. Making use of the benchmarking parameters discussed in Section 2, the electrocatalytic performance of the most relevant Ru-containing nanoparticulated systems for the OER under acidic and basic conditions are summarized in Table 1 and Table 2, respectively. Graphical representations of $\eta_{10} / b$ (where $b$ is the slope of the Tafel plot, Figure 2) and TOF (Figure 3) for the same set of OER electrocatalysts are also provided and discussed along this section. As deduced from the black columns in Figure 2, most Tafel slopes are comprised between 50 and $60 \mathrm{mV} \cdot \mathrm{dec}^{-1}$, falling within the normal range observed for different metal oxides in the literature. ${ }^{[23]}$ 
a)

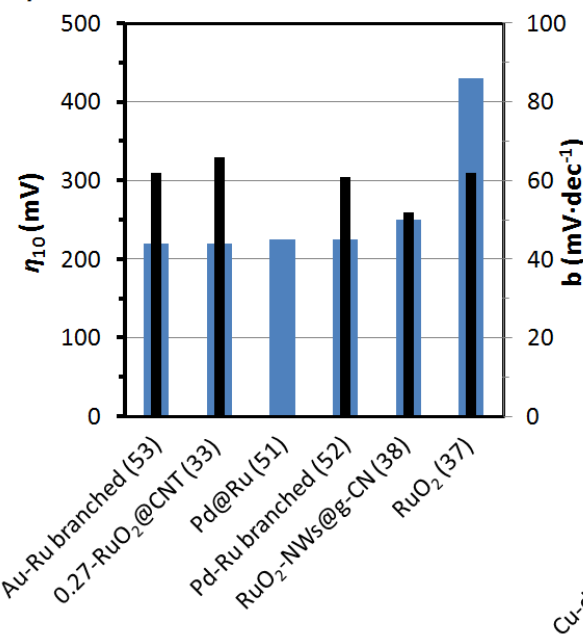

b)

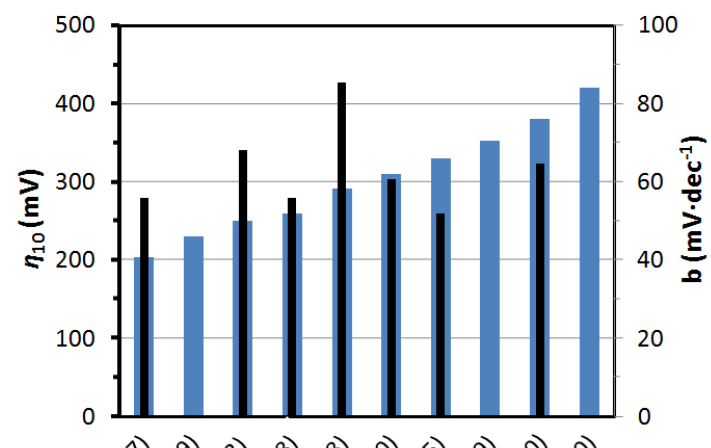

100

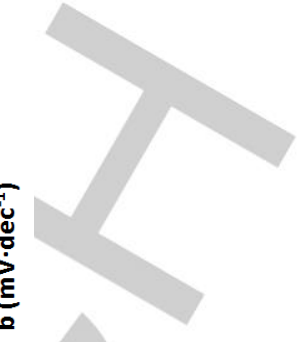

Figure 2. $\eta 10$ (blue) and Tafel slope b (black) for the most relevant OER electrocatalysts in (a) acidic and (b) alkaline aqueous solution.



Figure 3. Graphical comparison of TOF vs. overpotential data for OER electrocatalysts in acidic (green) and alkaline (brown) aqueous solution.

\subsection{Non-supported systems prepared ex situ.}

A majority of the Ru-based nanocatalysts (either metallic Ru or $\mathrm{RuO}_{2} \mathrm{NPs}$ ) assayed in the OER have been electrochemically triggered through deposition of the pre-catalytic entities onto RDE-GC. However, as noted above in Section 2, important difficulties arise when comparing the activity of the set of reported systems due to lack of homogeneity in electrode preparation methods, catalyst loadings and electrochemical test conditions. Thus, the following discussion will only focus on relevant contributions where benchmarked data are available, from which useful and accurate comparative information can be extracted.
A contribution from Stephens, Chorkendorff and co-workers[8] that constitutes one of the state-of-the art works and where the authors compare their results with other relevant data when appropriate is a good starting point to discuss about the factors ruling the activity and stability of Ru-based NPs in the OER. These authors carefully analyze the OER mass activity and stability (corrosion) in acidic media $\left(0.05 \mathrm{M} \mathrm{H}_{2} \mathrm{SO}_{4}\right)$ of both asdeposited and thermally oxidized $\left(400{ }^{\circ} \mathrm{C}, 1\right.$ bar $\left.\mathrm{O}_{2}, 1 \mathrm{~min}\right) \mathrm{Ru}-$ based NPs prepared through magnetron sputtering. This preparation method allows a high control over the size (in the range 2-9 $\mathrm{nm}$ depending on the conditions applied) and mass of the particles together with very clean surfaces. Following the tendency observed for extended surfaces, ${ }^{[45]}$ the activity of the as-deposited NPs (composed by a mixture of metallic Ru and $\mathrm{RuO}_{2}$ as determined by XPS and XRD) is clearly higher than that of thermally oxidized NPs (identified as pure $\mathrm{RuO}_{2}$ ). OER mass activity $\left(0.6 \mathrm{~A} \cdot \mathrm{mg}^{-1}\right)$, specific activity $\left(0.32 \mathrm{~mA} \cdot \mathrm{cm}^{-2}\right)$ and TOF $\left(0.65 \mathrm{~s}^{-1}\right.$ for $\eta=250 \mathrm{mV}$, Table 1 , entry 1$)$ data for the $\mathrm{RuO}_{2}$ system were calculated from the known mass and surface area of spherical particles and compared with literature data. The different figures of merit listed above resulted one order of magnitude higher than those found for any other NP in acidic medium, ${ }^{[31,37,46]}$ which is attributed by the authors to the clean surfaces provided by the preparation method. This is particularly clear when the performance of this system is compared with that of the chemically prepared $6 \mathrm{~nm} \mathrm{RuO}_{2} \mathrm{NPs}$ reported by ShaoHorn and co-workers, ${ }^{[37]}$ which have similar size and crystallinity but clearly lower specific activity $\left(0.010 \mathrm{~mA} \cdot \mathrm{cm}^{-2}\right.$, Table 1 , entry 2). Finally, the electroactivity of $\mathrm{RuO}_{2}$ sites in the OER has been proven to be sensitive to the presence of heteroatoms (heteroatom inducement). A first example by Chen and coworkers reported very active $\mathrm{Cu}$-doped $\mathrm{Ru}-\mathrm{RuO}_{2} \mathrm{NPs}$ (Table 2, entry 5), ${ }^{[47]}$ where, according to DFT calculations, the Cu doping allows tailoring the $d$-band centre of the $\mathrm{RuO}_{2}$ active sites. A 
second report on the same subject placed in good position a catalyst made of $\mathrm{Ru} / \mathrm{RuO}_{2}$ sites at the surface of $\mathrm{Co}_{x} \mathrm{P}$ hollow polyhedra (Ru-RuPx$-\mathrm{Co}_{x} \mathrm{P}$, Table 2, entry 6). ${ }^{[48]}$ The high electrocatalytic OER performance observed is attributed to both the synergism of the two metals present and the high specific surface area of the hybrid nanomaterial.

Several authors have also studied the effect of the crystallinity degree of the employed Ru-based NPs on the OER. ${ }^{[29,36,43]} \mathrm{Lim}$ and co-workers ${ }^{[29]}$ recently reported the inferior efficiency ( $\eta_{0} 123$ $\mathrm{mV}$ higher) and stability of hydrous $\mathrm{RuO}_{2}$ particles of low crystallinity with regards to those of its crystalline counterpart (prepared by annealing of the former at $300{ }^{\circ} \mathrm{C}$ ) in $1 \mathrm{M} \mathrm{KOH}$ (Table 2, entries 2 and 3 ). In terms of overpotentials, this result differs from the results described for $\mathrm{RuO}_{2}$ thin films. ${ }^{[49]}$ The inverse trend is reported by $\mathrm{Han}$ and co-workers when analyzing metallic $\mathrm{Ru}$ NPs of different crystallinity. ${ }^{[6]}$ The higher performance observed for amorphous Ru NPs has been attributed to the higher number of coordinatively unsaturated surface sites available in this type of material. Very recently, highly active partially hydrous $5 \mathrm{~nm} \mathrm{RuO} 2 \mathrm{NPs}$ embedded in a carbon matrix ( $\mathrm{x}-\mathrm{RuO}_{2} @ \mathrm{C}$ with $\mathrm{x}=$ hydration degree =0.27) have been reported as OER electrocatalysts both at acidic and basic $\mathrm{pH}$ (Table 1, entry 7; Table 2, entry 8 ). ${ }^{[33]}$ Their excellent OER activity has been related to the abundantly pre-existent hydroxyl species (-Ru-OH) in hydrous $\mathrm{RuO}_{2}$, which possibly accelerate the deprotonation step to generate the oxyspecies (Ru-O) necessary to form the $\mathrm{Ru}-\mathrm{OOH}$ ones during the rds, together with the improved proton conduction throughout hydrous $\mathrm{RuO}_{2}$. Thus, no clear trend can be extracted with the existent literature and more systematic research is desirable in this regard.

The stability of Ru-based NPs under OER conditions is another key issue to have at disposal durable electrodes for practical applications. When comparing the stability of their two systems, Stephens, Chorkendorff and co-workers[8] report important corrosion of the as-deposited $\mathrm{Ru} / \mathrm{RuO}_{2} \quad \mathrm{NPs}$, observing dissolution from the electrode by electrochemical scanning tunneling microscopy (EC-STM), but relatively stable pure $\mathrm{RuO}_{2}$ samples. This trend is in agreement with previous contributions that claim the higher stability of $\mathrm{RuO}_{2} v s$. $\mathrm{Ru} / \mathrm{RuO}_{2} \mathrm{NPs}$ in the OER and the easy transformation of metallic $\mathrm{Ru}$ into $\mathrm{RuO}_{4}$ under catalytic conditions (either acidic or basic) and consequently, its

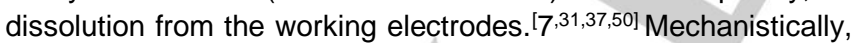
the work of Kötz et al. ${ }^{[50]}$ describes the formation of a Ru $\mathrm{VI}^{\mathrm{V}}$ intermediate $\left(\mathrm{RuO}_{2}(\mathrm{OH})_{2}\right)$ from both $\mathrm{Ru}$ and $\mathrm{RuO}_{2}$ at acidic $\mathrm{pH}$ prior to the formation of the $\mathrm{RuO}_{4}$ species. Since the structure of the $\mathrm{Ru}^{\mathrm{VI}}$ intermediate matches the crystal structure of $\mathrm{RuO}_{2}$ and not that of $\mathrm{Ru}$, the bonding with the former is stronger, thus decreasing its corrosion into $\mathrm{RuO}_{4}$. Another particularly remarkable work is that of Strasser and co-workers, ${ }^{[31]}$ where the electrocatalytic OER activity and stability of metallic $\mathrm{Ru}, \mathrm{Ir}$ and $\mathrm{Pt}$ NPs is compared with that of their corresponding bulk counterparts. Even if Ru NPs show the best initial specific activity, important passivation and corrosion is observed from the first $\mathrm{CV}$ scan, forming water-soluble $\mathrm{RuO}_{4}$ at potentials close to those needed for the OER. Remarkably, an alternative system for improving the stability of the Ru NPs while maintaining or even increasing their activity in the OER has been shown to be the combination of the $\mathrm{Ru}$ element with a more stable noble metal, less prone to undergo oxidation. Thus, Tilley and coworkers reported Pd@Ru core-shell NPs ${ }^{[51]}$ or $\mathrm{Pd}-\mathrm{Ru}^{[52]}$ and $\mathrm{Au}-$ $\mathrm{Ru}^{[53]}$ branched and faceted NPs, with $\eta_{10}$ values of $220-230 \mathrm{mV}$ and Tafel slopes of $61-62 \mathrm{mV} \cdot \mathrm{dec}^{-1}$ in $0.1 \mathrm{M} \mathrm{HClO}_{4}$ (Table 1, entries 4-6). The first work demonstrates that the $\mathrm{Pd}$ core stabilizes the Ru shell by up to ten times while maintaining the activity, ${ }^{[51]}$ whereas the other two show that the presence of branches increases both the stability and activity of the NPs as compared to the respective bimetallic spherical systems. ${ }^{[22,53]}$

\subsection{Systems arising from the decomposition of molecular complexes under OER conditions.}

Contrasting with other transition metals (TMs), works describing Ru-based NPs for the OER generated under catalytic conditions from the oxidative decomposition of molecular complexes are scarce. This is in agreement with the intrinsic robustness of $\mathrm{Ru}$ molecular WOCs containing ligands that are not easily oxidized or, when properly designed, that are oxidized at a sufficiently slow rate so their degradation is negligible. ${ }^{[11]}$ Among the most easily oxidizable organic substrates are those containing methylenic groups in benzyls, benzylalcohols and benzylpyridyls. Some complexes including these groups have been prepared, but a careful analysis of their behavior evidenced their degradation. ${ }^{[54,55,56]}$ In fact, a detailed study by simultaneously measuring the amount of $\mathrm{O}_{2}$ and $\mathrm{CO}_{2}$ generated showed the formation of the latter from the very beginning. This implies that massive ligand degradation occurs together with the formation of $\mathrm{O}_{2}$, and thus points to the formation of $\mathrm{RuO}_{2}$ as the active species rather than the initial molecular complex. A relevant example of ligand degradation is the case of the complex [Ru(bda) $\left.\left(\mathrm{N}-\mathrm{NH}_{2}\right)_{2}\right]$ (bda ${ }^{2-}$ is [2,2'-bipyridine]-6,6'-dicarboxylate, $\mathrm{N}-\mathrm{NH}_{2}$ is 4-(pyridin-4-yl)aniline) anchored to a glassy carbon surface. ${ }^{[12]}$ This is an extremely robust WOC in homogeneous phase that forms $\mathrm{O}-\mathrm{O}$ bonds in a bimolecular manner via an intermolecular mechanism. Attached to the surface of a graphitic electrode, and therefore with restricted mobility, it cannot undergo dimerization. This involves accessing higher energy pathways to afford water oxidation, which in parallel facilitate ligand degradation. As a result, after a few catalytic cycles the only $\mathrm{Ru}$ species left at the electrode surface are $\mathrm{RuO}_{2} \mathrm{NPs}$. With a TOF $\mathrm{T}_{\mathrm{i}}$ of $300 \mathrm{~s}^{-1}$ at $\Gamma=1.0 \mathrm{pmol} \cdot \mathrm{cm}^{-2}$, this system outperforms by several orders of magnitude the state-of-the-art systems prepared ex situ (see TOF data in Tables 1 and 2) and it has been incorporated in a photovoltaic-electrolyzer cell (PV-EC) together with an earth abundant cathode and a triple junction polymer cell, achieving solar to hydrogen conversion efficiencies of around $6 \% .{ }^{[57]}$ The reasons for the strikingly fast kinetics of this in situ-generated $\mathrm{RuO}_{2}$ electrocatalyst still remain unraveled.

\subsection{Supported systems.}

As noted in Section 3.1, the deposition of NP-based systems onto electrode surfaces for the electrocatalytic assessment of their OER performance is a common practice. Therefore, 
despite the use of electrodes is general, in most contributions they merely act as conducting supports for the colloidal catalysts. Hence, this section will only highlight contributions where the support is relevant for the catalytic performance of the catalyst and its role thoroughly discussed. Furthermore, in order to properly compare the reported results, it is useful here to group the systems on the basis of type of triggering energy used, which can be chemical, electrochemical or photochemical.

\subsubsection{Chemical and electrochemical systems.}

The preferably used chemical oxidant has clearly been $\mathrm{Ce}(\mathrm{IV})$, an outer-sphere one-electron oxidant with a high $\mathrm{Ce}(\mathrm{IV} / \mathrm{III})$ redox potential, widely employed in the OER both for metal oxides and molecular catalysts. In this respect, Ren and co-workers reported the embedding of pre-formed $1.6 \mathrm{~nm} \mathrm{RuO}_{2} \mathrm{NPs}$ into mesoporous silica (SBA-15, $\approx 6 \mathrm{~nm}$ pore size). ${ }^{[32]}$ The soobtained $\mathrm{RuO}_{2} @ S B A-15$ nanomaterial shows higher TOF than any reported system in $\mathrm{SiO}_{2}\left(\mathrm{TOF}_{\max }=0.27 \mathrm{~s}^{-1}\right)$ and a TON over 200 after recycling the catalyst more than 15 times. This high activity is attributed to a confinement effect of the $\mathrm{RuO}_{2} \mathrm{NPs}$ in the pores of the SBA-15 matrix, which prevents crystal growing during annealing and thus allows to get a metal oxide of small size and low crystallinity. Additionally, given the large pore size of the silica support, the catalyst presents a highly approachable surface area. This hypothesis is in agreement with the reduced activity reported for $\mathrm{RuO}_{2} \mathrm{NPs}$ of similar size when embedded in a mesoporous silica displaying pores as small as $2.7 \mathrm{~nm}$ $\left(\mathrm{TOF}_{\max }\right.$ of $\left.0.038 \mathrm{~s}^{-1}\right),{ }^{[58]}$ probably because the smaller pores lead to a limitation of the active surface area exposure. Low TON and TOF values (10 and $0.006 \mathrm{~s}^{-1}$, respectively) have been also recently obtained by Johnston and co-workers with subnanometric $\mathrm{RuO}_{2} \mathrm{NPs}$ embedded into a pyridine-functionalized siliceous mesocellular foam (MCF) arising from $\mathrm{RuCl}_{3}$ impregnation onto the support, followed by reduction with $\mathrm{NaBH}_{4}$ and air oxidation of the metallic Ru NPs formed. ${ }^{[41]}$

Martínez-Huerta and co-workers reported an electrochemicallytriggered system prepared through the polyol method where the support/electrode has a key role for the described performance. ${ }^{[59]}$ The system is bimetallic $\left(\mathrm{Pt}_{3} \mathrm{Ru}\right)$ and supported onto titanium carbonitride (TiCN). The supported system, where a $\mathrm{Ru} / \mathrm{RuO}_{2}$ mixture catalyzes the OER, shows enhanced activity and stability when compared to unsupported $\mathrm{RuO}_{2} \mathrm{NPs}$ in acidic conditions. Both effects are attributed to the TiCN support that is able of delaying catalyst aggregation and dissolution thanks to the formation of a $\mathrm{TiO}_{2}$ surface under turnover conditions. Also, Akbayrak, Önal and co-workers recently reported the facile preparation of a $\mathrm{Ru}(0) / \mathrm{CeO}_{2}$ system by chemically reducing $\mathrm{CeO}_{2}$-impregnated $\mathrm{Ru}^{3+}$ ions with $\mathrm{NaBH}_{4}{ }^{[60]}$ The hybrid system electrochemically catalyzes the OER at modest overpotentials $\left(\eta_{10}=420 \mathrm{mV}\right)$ and TOF values $\left(0.004 \mathrm{~s}^{-1}\right)$ but is nearly stable for $1000 \mathrm{CV}$ cycles in $0.5 \mathrm{M} \mathrm{KOH}$ (Table 2, entry 10). No analysis of the surface oxidation state evolution under OER conditions is provided. Finally, Zou and co-workers have recently reported a relevant OER electrocatalyst arising from the pyrolysis of a bimetallic CuRu-MOF, forming $\mathrm{Cu} / \mathrm{Ru}$ NPs onto a hierarchically porous carbon (HPC) matrix, followed by $\mathrm{Cu}$ NPs etching and thermal oxidation of the metallic Ru NPs (Ru-HPC) into $\mathrm{RuO}_{2} \mathrm{NPs}\left(\mathrm{P}-\mathrm{RuO}_{2}\right) .{ }^{[40]}$ The $5.64 \mathrm{~nm}$ average size $\mathrm{P}-\mathrm{RuO}_{2}$ system shows improved OER performance in $1.0 \mathrm{M} \mathrm{KOH}\left(\eta_{10}=\right.$ $310 \mathrm{mV}, \mathrm{b}=60.7 \mathrm{mV} \cdot \mathrm{dec}^{-1}$, Table 2, entry 11) when compared to commercial $\mathrm{RuO}_{2}$ (Table 2, entry 7) and is particularly interesting due to its stability (no sign of deactivation after 2000 CV cycles). The hierarchically porous structure of the hybrid material, which leads to a high exposure of the surface $\mathrm{RuO}_{2}$ active sites as demonstrated through BET and ECSA analysis, is proposed as the origin of its superior activity.

\subsubsection{Photochemical systems.}

In order to photo-catalytically test Ru-containing NPs in the OER, systems based on $\left[\mathrm{Ru}(\mathrm{bpy})_{3}\right]^{2+}$ as photosensitizer (PS) and $\mathrm{S}_{2} \mathrm{O}_{8}{ }^{2-}$ as sacrificial electron-acceptor (SEA) have been most commonly employed. $\left[\begin{array}{lll}41,42, & 61\end{array}\right]$ However, the use of semiconducting materials as light-harvesters has also been reported. ${ }^{[30]}$ Ren and co-workers provide a noteworthy example when photo-catalytically evaluating a $2^{\text {nd }}$ generation (with a better dispersed Ru phase) of their $\mathrm{RuO}_{2} @ S B A-15$ system (see Section 3.3.1. above). They reported $\mathrm{O}_{2}$ yields over $90 \%$, quantum efficiencies of ca. $10 \%$ and a TOF value of $2.7 \cdot 10^{-2} \mathrm{~s}^{-1}$ when combining their nanomaterial with $\left[\mathrm{Ru}(\mathrm{bpy})_{3}\right]^{2+}$ as PS and persulfate as SEA (Figure 4). ${ }^{[61]}$ This system outperforms many other metal oxides based on different TMs and the rest of lightdriven $\mathrm{RuO}_{2}$ systems reported to date, being recycled up to 5 times with minimal loss of activity. The authors attribute again the high activity observed to the large pores of the SBA-15 support, which allows an efficient interaction between the catalyst and the PS. Also, Johnston and co-workers ${ }^{[41]}$ reported the photocatalytic evaluation of their MCF-based system (vide supra). With a similar OER configuration, they attained a TON of 4 (moles of produced $\mathrm{O}_{2}$ per mole of $\mathrm{Ru}$ ) and one order of magnitude lower TOF of $2.2 \cdot 10^{-3} \mathrm{~s}^{-1}$. A different approach that aimed at facilitating electron transfer between the $\mathrm{RuO}_{2}$ catalyst and the PS was reported by Yoshida and co-workers. ${ }^{[42]}$ The described hydrogel system closely arranges pre-formed $\mathrm{RuO}_{2}$ $\mathrm{NPs}$ and $\mathrm{a}\left[\mathrm{Ru}(\mathrm{bpy})_{3}\right]^{2+}$-derivative by means of both electrostatic interactions between polar groups and steric confinement within a poly $(\mathrm{N}$-isopropyl)acrylamide polymeric matrix. A sustained production of oxygen was observed when the system was combined with $\left[\mathrm{Co}\left(\mathrm{NH}_{3}\right)_{5} \mathrm{Cl}\right]^{2+}$ as SEA and irradiated with visible light. Finally, Domen and co-workers have used an nsemiconductor TaON material doped with $\mathrm{RuO}_{2} \mathrm{NPs}$ of different sizes arising from the calcination of $\left[\left(\mathrm{NH}_{4}\right)_{2} \mathrm{RuCl}_{6}\right]$ at different temperatures. ${ }^{[30]}$ This RuNP-doped TaON system was compared with bare $\mathrm{TaON}$ under visible light irradiation and the presence of $\mathrm{S}_{2} \mathrm{O}_{8}{ }^{2-}$. The obtained results highlight the higher efficiency of the $\mathrm{RuO}_{2}$-based nanomaterial as OER photocatalyst and the critical role that the good dispersion of the metal oxide has on the catalytic performance. 


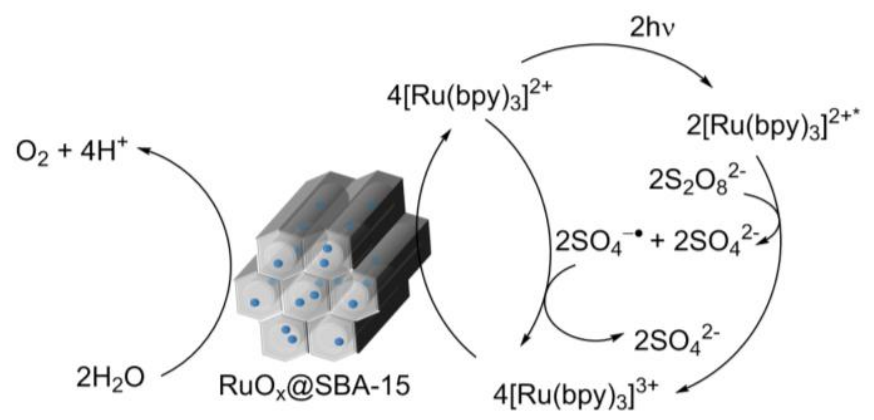

Figure 4. RuO ${ }_{2} @$ SBA-15 system designed for OER photocatalysis in the presence of $\left[\mathrm{Ru}(\mathrm{bpy})_{3}\right]^{2+}$ as PS and persulfate as SEA reported by Ren and co-workers. Adapted from ref. [61].

Table 1. Comparison of the most relevant Ru-based OER nanoelectrocatalysts under acidic conditions. Parameters: mean diameter ( $\varnothing)$ onset overpotential $\left(\eta_{0}, \mathrm{mV}\right)$, overpotential at $|j|=10 \mathrm{~mA} \cdot \mathrm{cm}^{-2}\left(\eta_{10}, \mathrm{mV}\right)$, Tafel slope $\left(\mathrm{b}, \mathrm{mV} \cdot \mathrm{dec}^{-1}\right)$, specific current density $\left(|j s|, \mathrm{mA} \cdot \mathrm{cm}^{-2}\right)$ and turnover frequency (TOF, $\mathrm{s}^{-1}$ ). Unless otherwise stated, electrolyte is $0.5 \mathrm{M} \mathrm{H}_{2} \mathrm{SO}_{4}$.

\begin{tabular}{|c|c|c|c|c|c|c|c|c|}
\hline Entry & Catalyst & $\varnothing(\mathrm{nm})$ & $\eta_{0}(\mathrm{mV})$ & $\eta_{10}(\mathrm{mV})$ & $b\left(\mathrm{mV} \cdot \mathrm{dec}^{-1}\right)$ & $|j \mathrm{~s}|\left(\mathrm{mA} \cdot \mathrm{cm}^{-2}\right)$ & $\operatorname{TOF}\left(\mathrm{s}^{-1}\right)$ & Ref. \\
\hline 1 & $\mathrm{RuO}_{2}{ }^{\mathrm{a}}$ & $3-5$ & $\approx 185$ & - & - & $0.32(250 \mathrm{mV})$ & $0.65(250 \mathrm{mV})$ & 8 \\
\hline 2 & $\mathrm{RuO}_{2}{ }^{\mathrm{b}}$ & $\approx 6$ & $\approx 220$ & 430 & 62 & $0.010(250 \mathrm{mV})$ & - & 37 \\
\hline 4 & $P d @ R u^{b}$ & $\approx 6 @ 0.5$ & $\approx 120$ & $220-230$ & - & $0.02(\approx 250 \mathrm{mV})$ & - & 51 \\
\hline 5 & Pd-Ru branched ${ }^{b}$ & $6.1 \times 9.1$ & $\approx 170$ & 225 & 61 & & - & 52 \\
\hline 7 & 0.27-RuO ${ }_{2} @ \mathrm{C}$ & 5 & $\approx 170$ & 220 & 66 & - & - & 33 \\
\hline
\end{tabular}

Electrolyte: [a] $0.05 \mathrm{M} \mathrm{H}_{2} \mathrm{SO}_{4}$ and [b] $0.1 \mathrm{M} \mathrm{HClO}_{4}$.

Table 2. Comparison of the most relevant Ru-based OER nanoelectrocatalysts under basic conditions. Parameters: mean diameter ( $)$, onset overpotential $\left(\eta_{0}, \mathrm{mV}\right)$, overpotential at $|j|=10 \mathrm{~mA} \cdot \mathrm{cm}^{-2}\left(\eta_{10}, \mathrm{mV}\right)$, Tafel slope $\left(\mathrm{b}, \mathrm{mV} \cdot \mathrm{dec}^{-1}\right)$, specific current density $\left(|j s|, \mathrm{mA} \cdot \mathrm{cm}^{-2}\right)$ and turnover frequency $\left(\mathrm{TOF}, \mathrm{s}^{-1}\right)$. Unless otherwise stated, electrolyte is $1.0 \mathrm{M} \mathrm{KOH} / \mathrm{NaOH}$.

\begin{tabular}{|c|c|c|c|c|c|c|c|c|}
\hline Entry & Catalyst & $\varnothing(\mathrm{nm})$ & $\eta_{0}(\mathrm{mV})$ & $\eta_{10}(\mathrm{mV})$ & $b\left(\mathrm{mV} \cdot \mathrm{dec}^{-1}\right)$ & $|j s|\left(m A \cdot \mathrm{cm}^{-2}\right)$ & TOF $\left(\mathrm{s}^{-1}\right)$ & Ref. \\
\hline 1 & $\mathrm{RuO}_{2}{ }^{\mathrm{a}}$ & $\approx 6$ & $\approx 220$ & - & 84 & $0.003(250 \mathrm{mV})$ & - & 37 \\
\hline 2 & hydrous $-\mathrm{RuO}_{2}$ & $<5$ & $\approx 290$ & 353 & - & - & - & 29 \\
\hline 3 & crystalline- $\mathrm{RuO}_{2}$ & - & $\approx 170$ & 230 & - & - & - & 29 \\
\hline 4 & $\mathrm{RuO}_{2}-\mathrm{NWs@g-CN}$ b & $10-40$ & 190 & 260 & 56 & - & $0.0995(350 \mathrm{mV})$ & 38 \\
\hline 5 & Cu-doped Ru-RuO $/ \mathrm{C}$ & $2.5-4.5$ & $\approx 155$ & 204 & 56 & - & - & 47 \\
\hline 6 & $\mathrm{Ru}-\mathrm{RuP}_{\mathrm{x}}-\mathrm{Co}_{x} \mathrm{P}$ & 2.4 & $\approx 240$ & 291 & 85.4 & - & - & 48 \\
\hline 7 & commercial $\mathrm{RuO}_{2}$ & $50-100$ & - & $380 \pm 20$ & 64.6 & $0.078(350 \mathrm{mV})$ & - & 20 \\
\hline
\end{tabular}




\begin{tabular}{llllllll}
8 & $0.27-\mathrm{RuO}_{2} @ \mathrm{C}$ & 5 & $\approx 200$ & 250 & 68 & - & - \\
9 & $\mathrm{PMCS}-\mathrm{Ru}^{\mathrm{c}}$ & 2.6 & $\approx 260$ & 330 & 52 & - & $0.002(300 \mathrm{mV})$ \\
10 & $\mathrm{Ru}(0) / \mathrm{CeO}_{2}{ }^{\mathrm{b}}$ & - & 340 & 420 & 122 & - & $0.004(350 \mathrm{mV})$ \\
11 & $\mathrm{P}-\mathrm{RuO}_{2}$ & 5.64 & $\approx 260$ & 310 & 60.7 & - & -60 \\
\hline
\end{tabular}

Electrolyte: [a] 0.1 M KOH and [b] 0.5 M KOH. [c] PMCS stands for pulsed microplasma cluster source. 


\section{Hydrogen Evolution Reaction}

The application of Ru-based nanocatalysts for the HER is a recent but fast-evolving field, with most of the relevant literature published in the 2016-19 period. Even if some photocatalytic examples exist (see Section 4.4 below), most of the reported systems are mainly constituted of Ru NPs deposited or supported/embedded onto conductive C-based (or even metallic) materials that are electrochemically triggered. The following sub-sections will thus emphasize the most outstanding nanomaterials reported and, particularly, the reasons that make them excel. A comparison of the most relevant HER electrocatalytic data of Ru-based nanoparticulated systems under acidic and basic conditions is given in Table 3 and Table 4, respectively. Additionally, graphical representations of $\eta_{10} / b$ (where $b$ is the slope of the Tafel plot, Figure 5) and TOF (Figure 6) for the same set of HER electrocatalysts are also provided and discussed along this section. As can be seen from the black columns in Figure 5, most Tafel slopes are comprised within a 30-40 $\mathrm{mV} \cdot \mathrm{dec}^{-1}$ range, thus indicating either Heyrovsky or Tafel step as the rds. However, some values stand above $40 \mathrm{mV} \cdot \mathrm{dec}^{-1}$ (up to $70 \mathrm{mV} \cdot \mathrm{dec}^{-1}$ ), either due to experimental inaccuracy and/or to the reported dependence of $b$ with applied potential. ${ }^{[25]}$ 
(a)

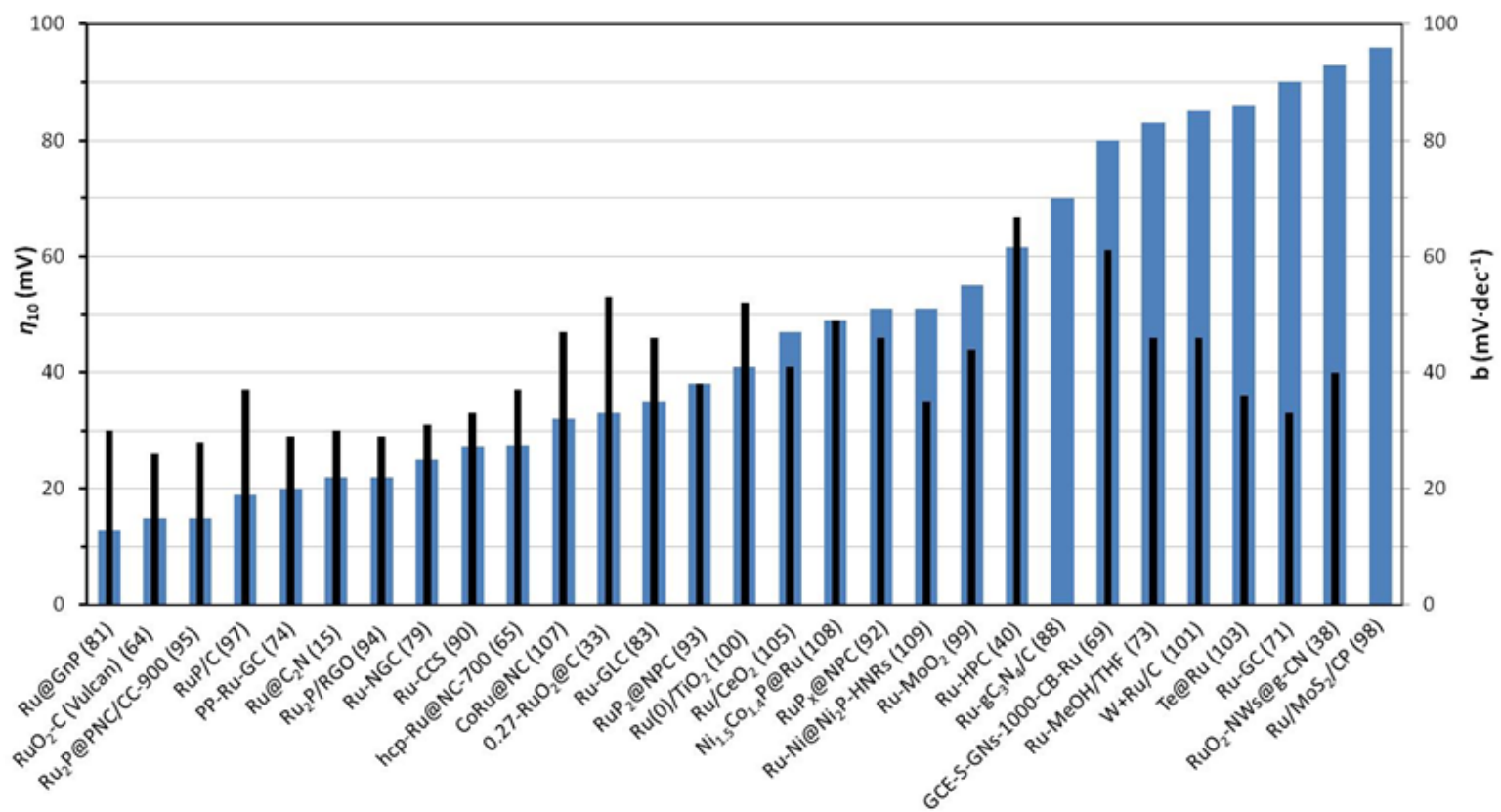

(b)

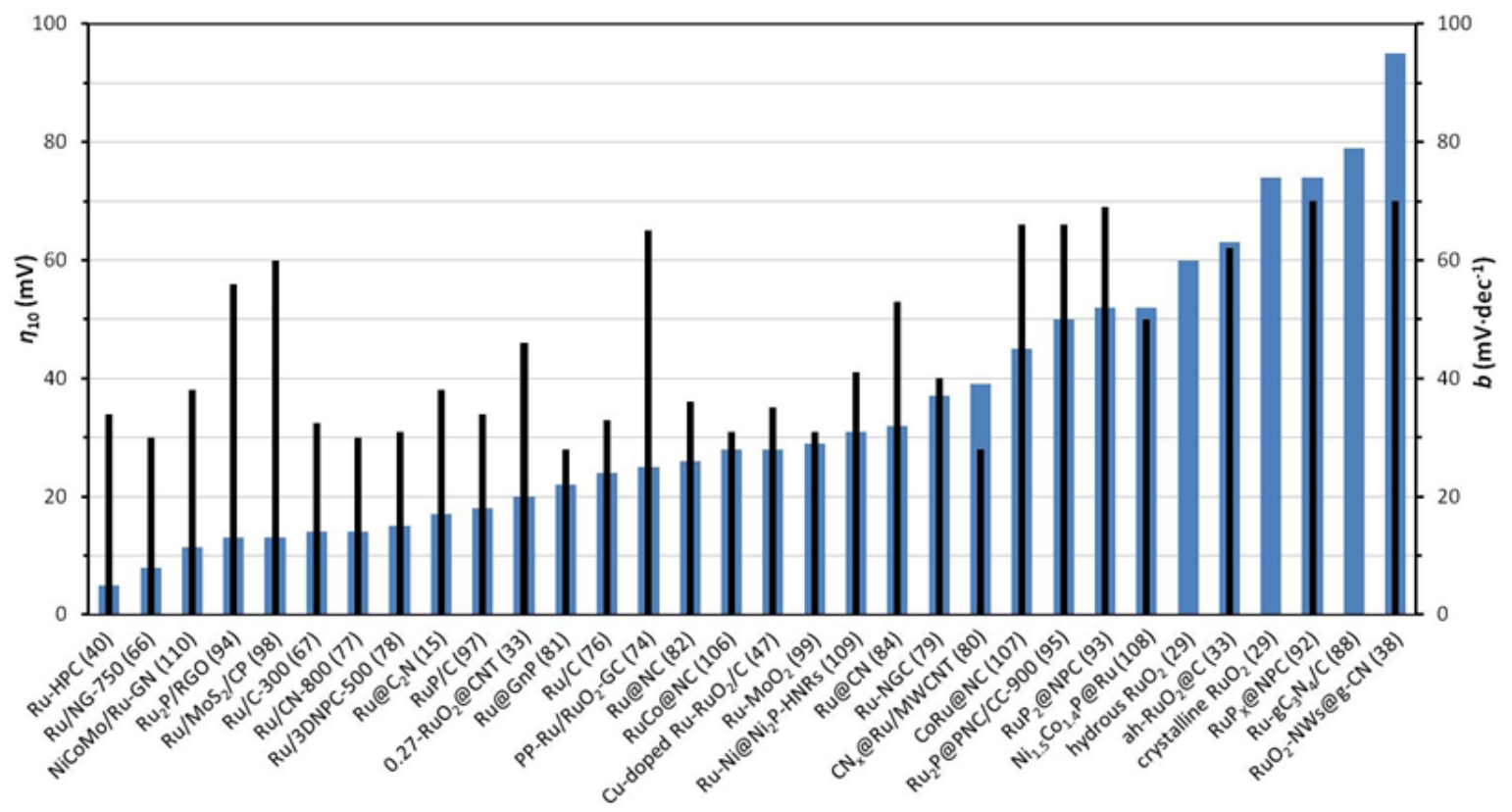

Figure 5. $\eta_{10}$ (blue) and Tafel slope b (black) for the most relevant HER electrocatalysts in (a) acidic and (b) alkaline aqueous solution. 
(a)



-들-PP-Ru-GC (74)

$-\leftrightarrow-\mathrm{Ru}-\mathrm{MeOH} / \mathrm{THF}$ (73)

- $-\mathrm{Ru} @ \mathrm{C}_{2} \mathrm{~N}$ (15)

- $\mathrm{Ru} / \mathrm{g}-\mathrm{C}_{3} \mathrm{~N}_{4} / \mathrm{C}(88)$

- $\mathrm{Ru} / \mathrm{CeO}_{2}(105)$

틀-Ru-Ni@Ni ${ }_{2}$ P-HNRs (109)

$\triangle$ hcp-Ru@NC-700(65)

- Te@Ru(103)

- Ru-HCP (40)

- Ru-NGC (79)

- Ru@GnP (81)

- RuP/C (97)

- Ru-CCS (90)

(b)

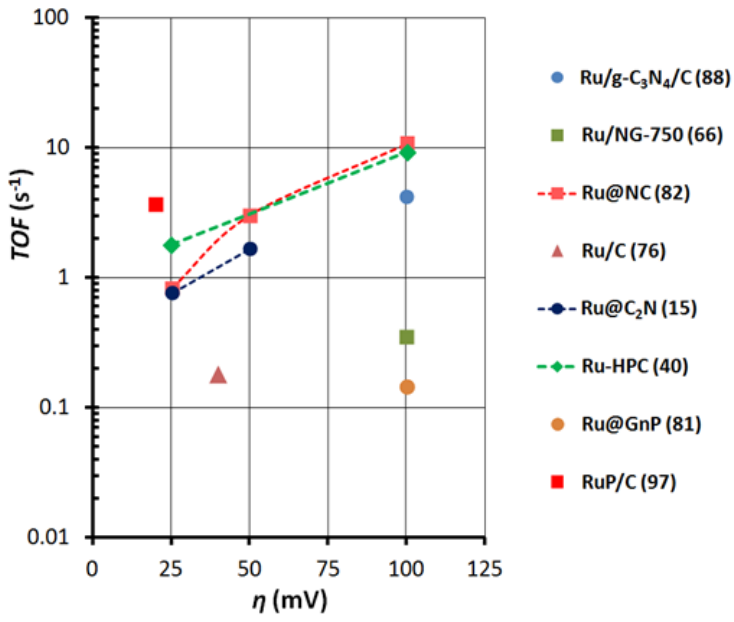

Figure 6. Graphical comparison of TOF vs. overpotential data for HER electrocatalysts in (a) acidic and (b) alkaline aqueous solution.

\subsection{Non-supported electrochemical systems prepared ex} situ.

Analogously to OER electrocatalysts, Ru-based nanoparticulated HER electrocatalysts have been prepared ex situ and then deposited onto the surface of $\mathrm{C}$-based materials (but also $\mathrm{Ni}$ foam or even silver epoxy), in order to facilitate electronic transfer under catalytic turnover and easily assess their electrocatalytic performance. In the majority of the cases the supporting electrode does not modify the intrinsic catalytic properties of the Ru-based NPs and it is in this sense that these systems have been considered as 'non-supported' in this section. Contrasting with the 'supported' systems that will be described in Section 4.2, where the supports used frequently dictate the catalytic performance and where the compositional complexity leaves hardly any space for the fine-tuning of the active sites, the non-supported systems such as those presented in this section are potentially better positioned in this regard.
Non-supported Ru-based NPs have been prepared through a myriad of methods such as the thermal decomposition/calcination of anhydrous $\mathrm{RuO}_{2},{ }^{[62]}$ a $\mathrm{Ru}$ salt ${ }^{[29,63}$, ${ }^{64,65]}$ or a Ru complex, ${ }^{[39,66,67]}$ or through the electro-reduction of a Ru salt, ${ }^{[68,69]}$ Ru perovskite-type precursor ${ }^{[70]}$ or Ru complex. ${ }^{[71]}$ However, the tailored synthesis and rational catalytic fine-tuning of non-supported Ru-based NPs is not a simple matter. First, the use of a stabilizer (typically a coordinating solvent, a ligand or the surface of a material) is mandatory in order to hold the systems at the nanoscale, preventing the formation of thermodynamically favored bulk species. Second, the metal oxidation state at the NP surface may evolve and even reversibly switch (typically between metallic $R u$ and $R u(I V)$ in $\mathrm{RuO}_{2}$ ) when in contact with air and/or under (electro)catalytic turnover conditions (see below). Thus, having at disposal an effective way to synthesize Ru-based NPs with controlled size, shape, oxidation state and surface composition is of utmost interest. In this regard, the so-called organometallic method, based on a controlled decomposition under mild conditions (e.g. 3 bar of $\mathrm{H}_{2}$, r.t.) of an organometallic olefinic $\mathrm{Ru}$ precursor in the presence of a stabilizing agent (often a ligand) is particularly well-suited, yielding clean surfaces and a set of surface hydrides that can be easily titrated. ${ }^{[72]}$ In addition, the ligand added for the synthesis and present on the surface of the NPs may play a key role on the overall HER activity of the nanocatalysts, potentially influencing the electronic properties of the NP surface, the number and disposition of the active (hydridic) sites available and even the mechanistic pathways through which $\mathrm{H}_{2}$ is formed. This resembles the characteristics of molecular metal-organic compounds in catalysis and makes such Ru NPs highly interesting systems for finely studying their catalytic properties in HER. As a first result, we have recently published significantly active $\mathrm{Ru}$ NPs stabilized in MeOH/THF and deposited onto GC electrodes.[ $\left.{ }^{73}\right]$ This catalytic system demonstrated the advantages of using the organometallic approach to obtain highly homogeneous NPs with very high active surface areas free of strongly coordinated stabilizers. Thus, the $21.4 \mathrm{~nm}$ porous Ru NPs show in $0.5 \mathrm{M} \mathrm{H}_{2} \mathrm{SO}_{4} \eta_{0} \approx 0 \mathrm{mV}, \eta_{10}=83 \mathrm{mV}$, a Tafel slope of $46 \mathrm{mV} \cdot \mathrm{dec}^{-1}$, a TOF $100 \mathrm{mv}$ of $0.87 \mathrm{~s}^{-1}$, a Faradaic efficiency of $97 \%$ and excellent durability up to $12 \mathrm{~h}$ (Table 3 , entry 19). Also, more recently, we have synthesized very small 4-phenylpyridine(PP)-capped Ru NPs (mean size $1.5 \mathrm{~nm}$ ), ${ }^{74,75]}$ which have been afterwards drop-casted onto a GC electrode for electrochemical analysis (PP-Ru-GC) and thoroughly characterized under air and HER turnover conditions in both acidic and basic conditions. The surface of these Ru NPs spontaneously oxidizes to $\mathrm{RuO}_{2}$ upon air exposure, yielding a mixed $\mathrm{Ru} / \mathrm{RuO}_{2}$ system where the PP ligand is still present. Although this mixed $\mathrm{Ru} / \mathrm{RuO}_{2}$ system is less active towards HER compared to pure Ru NPs, it can be converted into the metallic $\mathrm{Ru}$ form under reductive conditions (20 min-bulk electrolysis at $10 \mathrm{~mA} \cdot \mathrm{cm}^{-2}$ ) at acidic $\mathrm{pH}$ (Figure 7). ${ }^{[7]}$ Thus, the recovered PPRu-GC system exhibits $\eta_{0} \approx 0 \mathrm{mV}, \eta_{10}=20 \mathrm{mV}$, a Tafel slope of $29 \mathrm{mV} \cdot \mathrm{dec}^{-1}$ and a TOF as high as $17.4 \mathrm{~s}^{-1}$ at $\eta=100 \mathrm{mV}$ in $1 \mathrm{M}$ $\mathrm{H}_{2} \mathrm{SO}_{4}$, showing complete stability after $12 \mathrm{~h}$ of continuous operation (Table 3 , entry 25). A similar activation process under reductive potentials (but tentatively attributed to $\mathrm{RuO}_{2}$ structure 
deformation) had been previously reported by Zhang et al. for $\mathrm{C}$ supported 5-8 $\mathrm{nm} \mathrm{RuO}{ }_{2} \mathrm{NPs},{ }^{[64]}$ which formed a very active HER electrocatalyst at acidic $\mathrm{pH}\left(\eta_{0} \approx 0 \mathrm{mV}, \eta_{10} \approx 15 \mathrm{mV}\right.$ and Tafel slope of $26 \mathrm{mV} \cdot \mathrm{dec}^{-1}$; Table 3, entry 1). Despite being out of the nanoscale domain, the phase transformation of the $\mathrm{RuO}_{2}$ coating (0.4-1.4 $\mu \mathrm{m})$ of $\mathrm{RuO}_{2} / \mathrm{Ni}$ electrodes, first into $\mathrm{RuO}(\mathrm{OH})_{2}$ and then into metallic Ru under hydrogen evolution conditions, has also been reported by Näslund and co-workers through a careful analysis combining XRD and XPS. ${ }^{[63]}$ In contrast, in $1 \mathrm{M}$ $\mathrm{NaOH}$ the only stable form of our PP-Ru-GC system is the mixed $\mathrm{Ru} / \mathrm{RuO}_{2}$ form, yielding a slightly less active and stable system, although still outperforming the performance and stability of commercial Pt/C (Table 4, entry 26). We proposed that the presence of the PP capping agent induces good mechanical stability, thus allowing the maintenance of the nanostructured character of the material even after a long run. This hypothesis is supported by DFT calculations, which show the coordination of eleven PP molecules onto the surface of a $\mathrm{Ru}_{55} \mathrm{H}_{53} \mathrm{NP}$ both through $\mathrm{N}-\sigma$ and $\pi$-coordination modes, the latter being more stable and preferentially taking place on the edges of the NP. Furthermore, the d-band energy levels of the surface $\mathrm{Ru}$ atoms are significantly modified by the presence of hydride ligands, which have a stabilizing effect, whereas these energy levels are not significantly altered by the PP capping ligands, thus indicating a moderate adsorption strength of the latter onto the NP surface. In consequence, a larger number of hydride ligands are present on the NP surface compared to PP (53 vs. 11), thus accounting for its enhanced $\mathrm{H}_{2}$ evolution behavior.
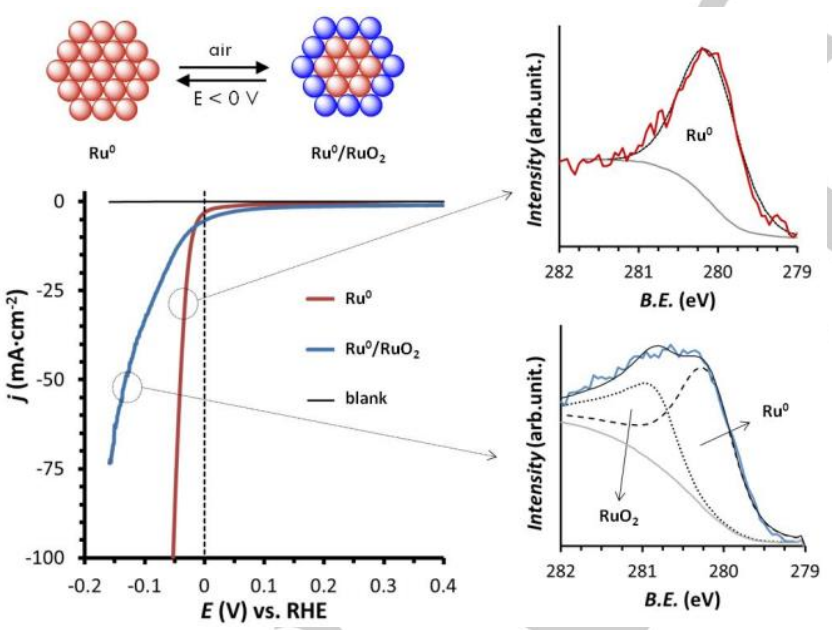

Figure 7. Polarization curves in a $1 \mathrm{M} \mathrm{H}_{2} \mathrm{SO}_{4}$ solution at $10 \mathrm{mV} \cdot \mathrm{s}^{-1}$ and XPS data of metallic PP-Ru NPs and their $\mathrm{Ru}(0) / \mathrm{RuO}_{2}$ surface-passivated counterpart formed upon air exposure. Adapted from ref. [74].

In terms of scalable and cost-effective methods for the production of active Ru-based nanoparticulated systems for the HER, Fan, Hu and co-workers have recently reported the solidstate synthesis of Ru NPs. These NPs were simply prepared by mixing at room temperature $\mathrm{RuCl}_{3}, \mathrm{NaOH}, \mathrm{NaBH}_{4}$ and a C source in an agate mortar. ${ }^{[76]}$ This led to very active, stable and homogeneous in size $(1.7 \mathrm{~nm}) \mathrm{Ru} N \mathrm{Ns}$ deposited onto $\mathrm{C}(\mathrm{Ru} / \mathrm{C})$ that show $\eta_{10}=24 \mathrm{mV}$ and a Tafel slope of $33 \mathrm{mV} \cdot \mathrm{dec}^{-1}$ at $\mathrm{pH} 14$ (Table 4, entry 27), thus improving again the performance of commercial $\mathrm{Pt} / \mathrm{C}$ in alkaline solution.

The degree of crystallinity is another critical issue ruling the activity and stability of nanoparticulated non-supported Rubased HER electrocatalysts that, as stated above for the OER, has not been thoroughly studied. Concerning $\mathrm{RuO}_{2} \mathrm{NPs}$, the works of Lim et al. ${ }^{[29]}$ and Song et al. ${ }^{[33]}$ show both a clear decrease of the HER activity after increasing the crystallinity of their initially hydrous $\mathrm{RuO}_{2} \mathrm{NPs}$ through annealing processes (see Table 4, comparison between entries 3 and 4 and entries 31 and 32, respectively). A word of caution: the surface oxidation state of the nanomaterial (initially $\mathrm{Ru}(\mathrm{IV})$ in $\mathrm{RuO}_{2}$ ) has not been analyzed after catalytic turnover under reductive conditions and thus the reduction to metallic $\mathrm{Ru}$ (as demonstrated in refs. 63 and 74 and discussed above) acting as the true active species cannot be discarded. A single very recent report by Qin, Bu, Liu and co-workers deals with the issue of crystallinity of metallic Ru NPs. ${ }^{[65]}$ The authors highlight the gradual increase in the HER activity of their Ru@NC system (NC $=\mathrm{N}$-doped $\mathrm{C}$ ) as the annealing temperature is increased up to $700{ }^{\circ} \mathrm{C}$. The $700^{\circ} \mathrm{C}$-annealed catalytic system displays high activity $\left(\eta_{10}=27.5 \mathrm{mV}\right.$, a Tafel slope of $37 \mathrm{mV} \cdot \mathrm{dec}^{-1}$ and a TOF of $1.6 \mathrm{~s}^{-1}$ at $\eta=25 \mathrm{mV}$ calculated through ECSA values, Table 3 , entry 30 ) and durability (up to $6 \mathrm{~h}$ and $20000 \mathrm{CV}$ cycles) in acidic conditions. DFT calculations show a gradual increased exposure of the more efficient (100) and (002) surfaces during the temperature-induced crystallization process as the reason for the increased activity of the highly crystalline hcp Ru NPs. Thus, the available data on non-supported systems point to amorphous $\mathrm{RuO}_{2}$-based NPs and highly crystalline Ru NPs as the species of choice for attaining high performance HER nanoparticulated electrocatalysts.

\subsection{Supported electrochemical systems on C- based/composite $\mathrm{C}$-based materials.}

In agreement with the definition of "non-supported" systems given in Section 4.1, the term "supported" here concerns Rubased nanoparticulated HER electrocatalysts where the support employed dictates (or markedly influences) the catalytic performance. As the section title suggests, the systems presented are based on either simple carbon supports (e.g. graphene) or more complex C-based multi-element composite materials (see below), where the Ru NPs are typically integrated by annealing a Ru precursor (usually a Ru salt or complex).

A first set of catalytic systems deals with the deposition of $R u$ NPs onto a conductive carbon-based matrix (e.g. carbon nitride, graphene or $\mathrm{N}$-doped graphene, hollow carbon spheres, etc.) through annealing of a $\mathrm{Ru}$ precursor. A relevant example by Tour and co-workers deals with Ru-nanoclusters deposited onto $\mathrm{N}$-doped graphene.[66] Their catalytic systems, prepared by nucleation of $\left[\mathrm{Ru}\left(\mathrm{NH}_{3}\right)_{6}\right]^{3+}$ as $\mathrm{Ru}$ precursor on graphene oxide (GO) at $160{ }^{\circ} \mathrm{C}$ followed by reduction under $\mathrm{NH}_{3} / \mathrm{Ar}$ at different temperatures $\left(350-850{ }^{\circ} \mathrm{C}\right)$, contain $\mathrm{Ru}$ nanoclusters of different 
average sizes, $\mathrm{Ru}$ average oxidation states, $\mathrm{N}$ contents, BET surface areas, pore size distributions and HER activities depending on the reducing temperature. Although slightly unstable under acidic HER conditions (probably due to dissolution), under alkaline conditions ( $\mathrm{pH} 14)$ the $5.8 \mathrm{~nm}$ nanoclusters formed at $750{ }^{\circ} \mathrm{C}$ showed impressive activity and stability (for 4000 LSV cycles), with $\eta_{0}=0 \mathrm{mV}, \eta_{10}=8 \mathrm{mV}$ and a Tafel slope of $30 \mathrm{mV} \cdot \mathrm{dec}^{-1}$ (Table 4 , entry 6). DFT calculations support the better performance of the system in alkaline HER conditions, which is attributed to the high $\mathrm{Ru}-\mathrm{H}_{2} \mathrm{O}$ binding energy at this $\mathrm{pH}$ and the corresponding increase of the $\mathrm{H}_{2} \mathrm{O}$ capture rate at the metal surface. The key role of $\mathrm{N}$-doping in $\mathrm{C}$ supported $\mathrm{Ru}$ nanoparticulate HER electrocatalysts in alkaline conditions is also supported by two recent contributions by Zhang, Fan and co-workers. ${ }^{[77,78]}$ These reports introduce $\mathrm{N}$ doping to C-black and $3 \mathrm{D}$ carbon supports through the pyrolysis of a $\left[\mathrm{Ru}(\mathrm{bpy})_{3}\right]^{2+}$ complex $^{[77]}$ or $\mathrm{RuCl}_{3} / \mathrm{urea}^{\left[{ }^{[78]}\right.}$ respectively, yielding ca. $1.3 \mathrm{~nm}$ supported Ru NPs in both cases as best performing systems. Both electrocatalysts show low HER overpotentials $\left(\eta_{10}=14-15 \mathrm{mV}\right)$ and relatively high stabilities in 1.0 M KOH (1000 CV cycles) that outperform those of $\mathrm{Pt} / \mathrm{C}$ (Table 4, entries 14 and 15). A thorough comparison with the corresponding undoped systems highlights the importance of $\mathrm{N}$ to avoid aggregation and boost the electrocatalytic activity. Analogously, N-doping of graphite C (NGC) has been an excellent strategy to boost the HER activity of Ru NPs both at acidic and basic $\mathrm{pH}$ (Table 3, entry 15; Table 4, entry 16), ${ }^{[79]}$ and the beneficial effect of a $\mathrm{C}$ nitride coating onto Ru NPs deposited on MWCNTs has been recently reported at pH 14 (Table 4, entry 17). ${ }^{[80]}$ However, in a recent paper the HER activity of Ru NPs deposited onto graphene nanoplatelets (Ru@GnP; Table 3, entry 16 ; Table 4 , entry 18$)^{[81]}$ has been shown to decrease after $\mathrm{N}$-doping due to the blocking of $\mathrm{Ru}$ active sites by $\mathrm{N}$ atoms. Excellent HER performance in alkaline conditions has also been recently reported by Yamauchi and co-workers by means of a hierarchically ordered system. ${ }^{[82]}$ As shown in Figure 8, the catalyst is prepared by a potential-controlled $(-0.2 \mathrm{~V}$ vs. SCE) assembly of $\left[\mathrm{Ru}(\mathrm{CN})_{6}\right]^{4-}$ units into the diluted oxidized units of a polyaniline fiber foam deposited onto carbon paper followed by a carbonization process at $900{ }^{\circ} \mathrm{C}$. Monodisperse $1.6 \mathrm{~nm} \mathrm{Ru}$ nanoclusters are thus deposited onto the surface of the $\mathrm{N}$-doped C support (Ru@NC). Very good HER activity and stability in alkaline solution $(\mathrm{pH} 14)$ were obtained with this nanomaterial at particularly low Ru loading ( $2 \% \mathrm{wt}$ ), showing a $\eta_{10}$ of only $26 \mathrm{mV}$, a Tafel slope of $36 \mathrm{mV} \cdot \mathrm{dec}^{-1}$ and an impressive TOF $100 \mathrm{mv}$ of 10.8 $\mathrm{s}^{-1}$, as well as an excellent stability after $12 \mathrm{~h}$ or 10000 cycles (Table 4, entry 13). Interestingly, its mass activity at $\eta=100 \mathrm{mV}$ (17 A. $\mathrm{mg}^{-1} \mathrm{Ru}$ ) is 6.8 times that of a commercial $\mathrm{Pt} / \mathrm{C}$ catalyst displaying a Pt loading of $20 \%$. These comparative results evidence the importance of the location of the metallic NPs on the support: deposition onto the surface of the conductive $\mathrm{C}$ support and not inside the $\mathrm{C}$ matrix where the reaction may be hampered leads to better activity. A second prominent hierarchical composite HER electrocatalyst is Ru-HPC ${ }^{[40]}$ arising from the pyrolytic decomposition of a CuRu-MOF, the oxidized version of this system $\left(\mathrm{P}-\mathrm{RuO}_{2}\right)$ has already been discussed as an OER electrocatalyst in Section 3.1.1 (see above). In $1.0 \mathrm{M}$ $\mathrm{KOH}$, the Ru-HPC composite clearly outperforms commercial $20 \% \mathrm{Pt} / \mathrm{C}$, achieving $\eta_{25}=22.7 \mathrm{mV}, \eta_{50}=44.6 \mathrm{mV}$, a Tafel slope of $33.9 \mathrm{mV} \cdot \mathrm{dec}^{-1}$ and a TOF $25 \mathrm{mv}$ of $1.79 \mathrm{~s}^{-1}$ (Table 4, entry 19), showing total stability after $10 \mathrm{~h}$ of continuous operation. The bimetallic MOF-templated synthetic strategy adopted by the authors is at the core of the outstanding results obtained and it relays on (a) the uniform distribution and adjustable concentration of Ru sites in the CuRu-MOF precursor employed, (b) the $\mathrm{Cu}$ etching strategy applied resulting in an increased exposition of $\mathrm{Ru}$ active sites and (c) the high surface area and highly porous nature of the hierarchical C-based structure formed. Ru-HPC has also been tested in acidic media $(0.5 \mathrm{M}$ $\mathrm{H}_{2} \mathrm{SO}_{4}$ ) but the obtained results are average among Ru-based nanomaterial electrocatalysts (Table 3 , entry 17). Comparable catalytic results that outperform the HER activity of commercial $\mathrm{Pt} / \mathrm{C}$ in alkaline solution have been obtained by Zhang and coworkers by using a catalyst made of $1.5 \mathrm{~nm}$ Ru NPs onto C prepared upon adsorption of $\left[\mathrm{Ru}_{3}(\mathrm{CO})_{12}\right]$ on the $\mathrm{C}$-matrix followed by pyrolysis at $300{ }^{\circ} \mathrm{C}(\mathrm{Ru} / \mathrm{C}-300) \cdot{ }^{[67]}$ In $1.0 \mathrm{M} \mathrm{KOH}$, the $\mathrm{Ru} / \mathrm{C}-300$ nanomaterial achieves $\eta_{0} \approx 0 \mathrm{mV}, \eta_{10}=14 \mathrm{mV}$ and Tafel slope of $32.5 \mathrm{mV} \cdot \mathrm{dec}^{-1}$ (Table 4, entry 25), showing almost total stability after 1000 cycles as the result of the deposition of the $\mathrm{Ru} \mathrm{NPs}$ onto the $\mathrm{C}$ matrix. Furthermore, this work demonstrated that the pyrolysis temperature affects the size and dispersion of the NPs formed, which in turn modifies their HER catalytic activity. As a conclusion, the favorable $\mathrm{H}_{2} \mathrm{O}$ binding/dissociation energies make $\mathrm{Ru}$ outperform $\mathrm{Pt}$ under alkaline conditions. Conversely, Adschiri et al. showed the relatively similar behavior of the two metals in acidic conditions when analyzing the HER activity of $2-5 \mathrm{~nm} R u$ NPs onto graphene-layered carbon (GLC) (Table 3, entry 4) through both experimental and computational data. ${ }^{[83]}$ 




Figure 8. Schematic representation of the synthesis of the hierarchically-ordered N-doped carbon electrode containing $1.6 \mathrm{~nm}$ hcp-Ru nanoclusters (Ru@NC) reported by Yamauchi et al.[82] Color code: reduced polyaniline fibers, yellow; oxidised polyaniline fibers, violet.

A second relatively wide set of supported systems are those prepared by co-pyrolysis of $\mathrm{C}, \mathrm{N}$ and Ru sources. Thus, Wang and co-workers obtained $2.4 \mathrm{~nm} \mathrm{Ru} \mathrm{NPs}$ onto N-doped graphene-like nanosheets (Ru@CN) by co-pyrolysis of glucosamine, melamine and $\mathrm{RuCl}_{3 .}{ }^{[84]}$ Their Ru@CN system shows $\eta_{0} \approx 0 \mathrm{mV}$ and $\eta_{10}=32 \mathrm{mV}$ at $\mathrm{pH} 14$ and also excellent stability after 2000 CVs (Table 4, entry 12). This catalyst displays a 9 times higher mass activity than that of commercial $\mathrm{Pt} / \mathrm{C}$ while keeping $90 \%$ of the initial activity after $10 \mathrm{~h}$ of continuous operation at $60{ }^{\circ} \mathrm{C}$. The authors attribute this behavior to the strong interaction between $\mathrm{Ru}$ and $\mathrm{N}$ sites on the support, which avoids agglomeration and leaching of the $\mathrm{Ru}$ NPs. However, this system shows moderate activity at acidic (Table 3, entry 14) and neutral pH. Additionally, the strong effect of a composite carbon matrix prepared by a co-pyrolysis method in the $\mathrm{Ru}-\mathrm{H} / \mathrm{OH} / \mathrm{H}_{2} \mathrm{O}$ binding energies and $\mathrm{H}_{2} \mathrm{O}$ dissociation rates and, thus, in the HER electroactivity of the corresponding $\mathrm{Ru}$ NPs through the entire $\mathrm{pH}$ range has been emphasized by a prominent work of Baek and co-workers. ${ }^{[15]}$ They prepared a material made of $1.6 \mathrm{~nm}$ hcp-Ru NPs embedded into a nitrogenated holey two-dimensional carbon structure $\left(\mathrm{Ru} @ \mathrm{C}_{2} \mathrm{~N}\right)$ by polycondensation of hexaketocyclohexane and hexaaminobenzene in the presence of $\mathrm{RuCl}_{3}$, followed by a subsequent reduction with $\mathrm{NaBH}_{4}$ at $175{ }^{\circ} \mathrm{C}$. The so-obtained $\mathrm{Ru} @ \mathrm{C}_{2} \mathrm{~N}$ catalyst showed excellent HER performance both at acidic $\mathrm{pH}$ (with $\eta_{10}=22 \mathrm{mV}$ and a Tafel slope of $30 \mathrm{mV} \cdot \mathrm{dec}^{-1}$; Table 3, entry 7) and at basic $\mathrm{pH}$ (with $\eta_{10}=17 \mathrm{mV}$ and a Tafel slope of $38 \mathrm{mV} \cdot \mathrm{dec}^{-1}$; Table 4 , entry 2), improving the values for $\mathrm{Pt} / \mathrm{C}$ at $\mathrm{pH} 14$. Furthermore, the HER catalytic activity at acidic $\mathrm{pH}$ rises after 1000 cycles, reaching a $\eta_{10}$ of only $13.5 \mathrm{mV}$. DFT calculations on $\mathrm{Ru}_{55}$ models revealed the key role of the $\mathrm{C}_{2} \mathrm{~N}$ framework for the high electrocatalytic activity of the nanomaterial. In alkaline conditions, a significant increase of both the $\mathrm{Ru}-\mathrm{OH}_{2}$ binding energy (leading to faster water adsorption) and the rate of water dissociation (yielding faster proton supply) is observed. These effects, triggered by the $\mathrm{C}_{2} \mathrm{~N}$ matrix, compensate the unfavorably high $\mathrm{OH}$ binding energy on $\mathrm{Ru}$ (compared to $\mathrm{Pt}$ ) and increase its efficiency in the Volmer reaction and thus its whole HER efficiency. The beneficial effects of $\mathrm{C}_{2} \mathrm{~N}$-type of substrates in water splitting electrocatalysis, including stability against aggregation and high electroactivity, have also been raised by Zhou and co-workers by means of first-principles computations of a series of transition metal atom anchored $\mathrm{C}_{2} \mathrm{~N}$ monolayers, including $\mathrm{Ru}_{\mathrm{x}} @ \mathrm{C}_{2} \mathrm{~N}$ species. [85] A word of caution: individual ruthenium atoms embedded into $\mathrm{C}_{x} \mathrm{~N}_{\mathrm{y}}$ matrices have been recently identified as the true catalytic sites for HER in alkaline media, even if formed together with $\mathrm{Ru} \mathrm{NPs}$ through co-pyrolysis synthetic methods. ${ }^{[86,87]}$ These works emphasize the importance of structurally characterizing new electrode materials at atomic scale in order to unravel the nature of the real catalytic active species present.

It is noteworthy that despite metallic Ru usually adopts a hcp structure, different groups observed that the co-pyrolysis synthetic method led to either hcp, fcc or mixed hcp/fcc Ru phases in the final NPs. ${ }^{[47,88,89]}$ Assessment of the HER electroactivity of these systems evidences the positive influence of the fcc-Ru phase onto the final catalytic behavior in alkaline conditions (Table 4, entries 5 and 28). For example, Qiao and co-workers prepared fcc-structured $2 \mathrm{~nm}$ Ru NPs on graphitic carbon nitride $\left(\mathrm{g}-\mathrm{C}_{3} \mathrm{~N}_{4} / \mathrm{C}\right)$ starting from dicyandiamide and $\mathrm{RuCl}_{3} .{ }^{[88]}$ When drop-casted onto RDE-GC, the so-obtained $\mathrm{Ru} / \mathrm{g}-\mathrm{C}_{3} \mathrm{~N}_{4} / \mathrm{C}$ nanomaterial showed significant activity $\left(\eta_{0}=15-20\right.$ $\mathrm{mV}$ ) and stability for $50 \mathrm{~h}$ (Table 4 , entry 5 ), outperforming commercial $\mathrm{Ru} / \mathrm{C}$ and $\mathrm{Pt} / \mathrm{C}$ under identical conditions. The authors attributed these results to the atypical $\mathrm{Ru}$ structure that might be induced by the $g-\mathrm{C}_{3} \mathrm{~N}_{4}$ support. As shown in Figure 9 , this hypothesis is supported by theoretical data only when both thermodynamics (adsorption energies) and kinetics (water dissociation rates) are considered as activity descriptors. 
Thermodynamically, DFT calculations on selected metal surfaces showed $\mathrm{H}$ adsorption energies $\left(\Delta \mathrm{G}_{\mathrm{H}^{*}}\right.$ in Figure 9$)$ following the $\mathrm{Pt}<\mathrm{Ru}_{\mathrm{fcc}}<\mathrm{R} \mathrm{u}_{\mathrm{hcp}}$ trend. Thus, with the lowest $\mathrm{Ru}-\mathrm{H}$ strength, from the thermodynamic point of view Pt should show the highest HER activity. However, fcc-Ru shows the lowest water dissociation barrier $\left(\Delta G_{B}\right.$ in Figure 9$)$ among the three studied systems, while Pt shows the highest. Thus, the kinetics of water dissociation are favored for fcc-Ru at basic $\mathrm{pH}$, which results key for the observed HER performance. This work evidences the relevance of considering the kinetics of water dissociation when modeling the HER performance of Ru-based nanocatalysts in alkaline media. ${ }^{[88]}$
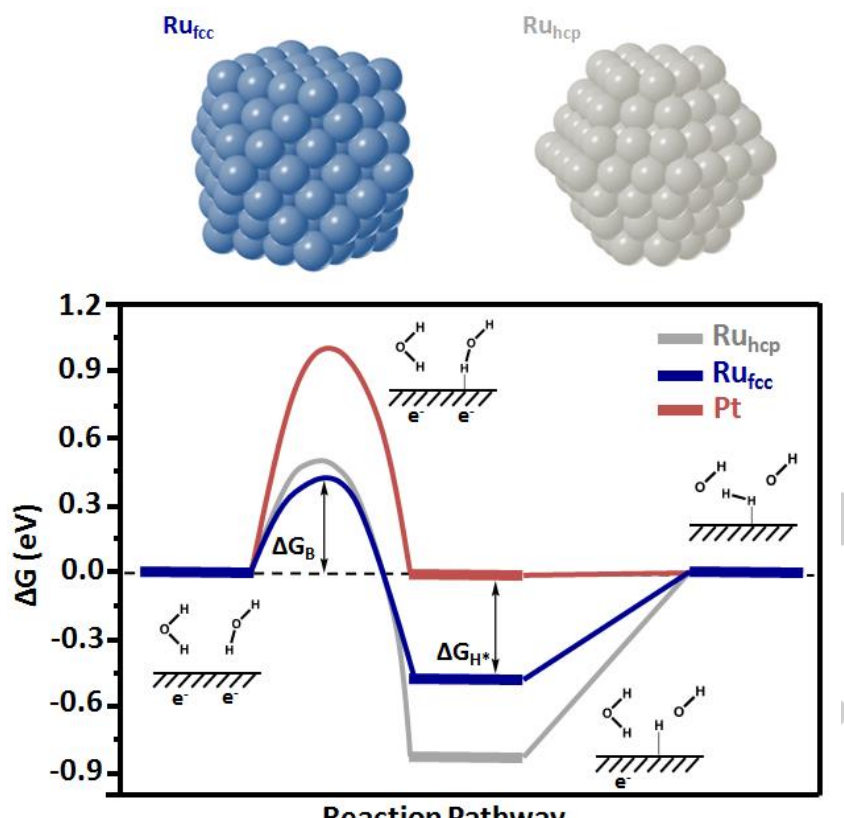

Reaction Pathway

Figure 9. Top: Representation of the anomalous fcc-Ru phase (left) and the habitual hcp-Ru phase (right). Bottom: Gibbs free energy diagram of HER on $R u_{f c c}$ (blue), Ruhcp (grey) and Pt (red) surfaces as reported by Qiao et al. [88]. $\Delta \mathrm{G}_{\mathrm{H}^{*}}$ corresponds to $\mathrm{H}$ adsorption free energy and $\Delta \mathrm{G}_{\mathrm{B}}$ corresponds to water dissociation free energy barrier. Adapted from ref. [88].

The beneficial effect of introducing heteroatoms onto the coordination sphere of $\mathrm{Ru}$ has also been demonstrated. For example, hcp-Ru NPs onto a carbonized collagen scaffold (RuCCS; Table 3, entry 8 ) by co-assembly of collagen and $\mathrm{RuCl}_{3}$ and subsequent pyrolysis at $800{ }^{\circ} \mathrm{C}$ under $\mathrm{Ar}^{[90]}$ show coordination to $\mathrm{P}$ and $\mathrm{S}$ atoms, which according to DFT calculations promote separation of electrons and holes and increase the amount of localized electrons on $\mathrm{Ru}$, therefore facilitating proton adsorption by lowering $\Delta \mathrm{G}_{\mathrm{H}}{ }^{*}$ close to zero. In this sense, the introduction of phosphorous into HER nanoparticulated electrocatalysts using phosphide containing transition metal NPs has been another common strategy. It is a way to take advantage of both the moderate $\mathrm{H}$ binding energy of $\mathrm{P}$ and the increase in corrosion resistance of the nanomaterials at acidic $\mathrm{pH}$ induced by the $\mathrm{P}$ presence, the latter improving their stability. ${ }^{[91]}$ Thus, for Ru NPs, the introduction of $P$ has been shown as extremely productive in HER catalysis in acidic conditions, but also at neutral and basic $\mathrm{pH}$, normally generating composite systems in which the effect of the C-based material has also been proven essential for preventing the aggregation and tuning the electronic properties of the NPs. ${ }^{[92,93,94,95]}$ For example, very stable HER catalytic systems at all $\mathrm{pHs}$ have been obtained by encapsulating RuP $\mathrm{P}_{\mathrm{x}} \mathrm{NPs}$ inside N,P-doped C shells ${ }^{[93]}$ (RuP ${ }_{2} @ N P C ;$ Table 3, entry 13; Table 4, entry 11) and nanospheres ${ }^{[92]}$ (RuP $@$ @NP; Table 3, entry 9; Table 4, entry 7). Two highly active system concerning the use of these $\mathrm{pH}$ versatile $\mathrm{RuP}_{\mathrm{x}} \mathrm{NPs}$ in $\mathrm{C}$-based supports have been recently reported by Chen, $\mathrm{Hu}$ et al. ${ }^{[94]}$ and $\mathrm{Li}$, Hu et al., ${ }^{[95]}$ in which the synergistic interaction between the NPs and the C-based support provokes an increase in electron mobility and a charge density redistribution between them, the latter inducing an optimal $\mathrm{H}$ adsorption energy close to 0 and thus highly active

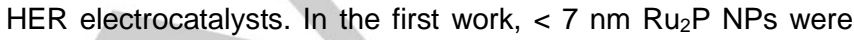
deposited onto reduced graphene oxide $\left(\mathrm{Ru}_{2} \mathrm{P} / \mathrm{RGO}\right)$ after a thermal hydrolysis of $\mathrm{RuCl}_{3}$ in the presence of $\mathrm{GO}$ and a subsequent phosphidation process, ${ }^{[94]}$ outperforming the activity and stability after $10 \mathrm{~h}$ of operation or 1000 cycles of those of $\mathrm{Pt} / \mathrm{C}$ both at acidic and basic $\mathrm{pH}$. They thus obtained some of the best values reported so far for HER catalysis in $0.5 \mathrm{M} \mathrm{H}_{2} \mathrm{SO}_{4}$ $\left(\eta_{0} \approx 0 \mathrm{mV}, \eta_{10}=22 \mathrm{mV}\right.$, Tafel slope $=29 \mathrm{mV} \cdot \mathrm{dec}^{-1}$ and $\left|j_{0}\right|=2.2$ $\mathrm{mA} \cdot \mathrm{cm}^{-2}$; Table 3 , entry 11$)$ and in $1 \mathrm{M} \mathrm{KOH}\left(\eta_{0} \approx 0 \mathrm{mV}, \eta_{10}=13\right.$ $\mathrm{mV}$; Table 4, entry 9). Contrasting to the huge majority of HER nanoparticulated catalysts based on noble metals, whose activity decreases at basic $\mathrm{pH}$ vs. acidic $\mathrm{pH}$ due to an increase in the hydrophobicity of the metal surface that hampers water adsorption, ${ }^{[96]} \mathrm{Ru}_{2} \mathrm{P} / \mathrm{RGO}$ shows lower $\eta_{10}$ values under alkaline conditions than under acidic conditions. According to DFT calculations partial electron transfer from $\mathrm{Ru}_{2} \mathrm{P}$ to the surface $\mathrm{sp}^{2}$ $\mathrm{C}$ of RGO favors water dissociation and the subsequent hydrogen adsorption and recombination. ${ }^{[94]}$ In the second recent work, even more active $\mathrm{Ru}_{2} \mathrm{P} N \mathrm{NS}$ at acidic $\mathrm{pH}$ have been obtained after calcination at $900{ }^{\circ} \mathrm{C}$ of polyaniline fibers on $\mathrm{C}$ cloth with a $\mathrm{RuCl}_{3} \cdot 3 \mathrm{H}_{2} \mathrm{O}$, yielding $\mathrm{Ru}_{2} \mathrm{P} N \mathrm{NP}$ partially encapsulated by a $\mathrm{C}$ layer and deposited on top of $\mathrm{P} / \mathrm{N}$-doped $\mathrm{C}$ nanofibers on $\mathrm{C}$ cloth $\left(\mathrm{Ru}_{2} \mathrm{P} @ \mathrm{PNC} / \mathrm{CC}-900 ;\right.$ Table 3, entry 12 , Table 4, entry 10). The superior HER performance is associated to the modification of $\Delta \mathrm{G}_{\mathrm{H}}{ }^{*}$ of $\mathrm{Ru}_{2} \mathrm{P}$ by the $\mathrm{P} / \mathrm{N}$-doped $\mathrm{C}$ surface, which boosts their proton adsorption and reduction capacities. ${ }^{\text {[95] }}$ Finally, although not being a supported composite system, extremely active and stable $\left(200 \mathrm{~h}\right.$ at $\left.10 \mathrm{~mA} \cdot \mathrm{cm}^{-1}\right) 32 \mathrm{~nm}$ RuP NP agglomerates on C (RuP/C, Table 3, entry 10; Table 4, entry 8) have been described both at acidic and basic $\mathrm{pH}$, with higher $\left|j_{0}\right|$ and TOF and lower $\eta_{10}$ and Tafel slopes than $20 \% \mathrm{Pt} / \mathrm{C}$ at $\mathrm{pH}$ 14 and comparable values at $\mathrm{pH} 0$. Curiously, the agglomerates show superior performance and stability than lower size NPs of $3 \mathrm{~nm}$ due to better stabilization of the $\mathrm{P}$ species for the former thanks to lowered surface energy of larger NPs. ${ }^{[97]}$

To summarize, the best performing supported Ru NP catalytic systems are composite materials prepared by two different pathways. First, the direct anchoring of a Ru precursor onto a carbon-based electrode followed by an annealing step that allows to form the Ru NPs onto the electrode; second, the 
condensation of organic precursors that direct the growth of $\mathrm{Ru}$ NPs followed by a carbonization process to form a conductive carbon matrix around the NPs. In these works, it has been proven the catalytic advantages for HER of $\mathrm{N}$-doped C-based supports that lead to increased stability and activity. Also, the appropriate values of the $\mathrm{H} / \mathrm{H}_{2} \mathrm{O}$ adsorption energy and $\mathrm{H}_{2} \mathrm{O}$ dissociation rate onto Ru NPs (especially in their fcc-phase for alkaline $\mathrm{HER}$ ) and $\mathrm{RuP}_{\mathrm{x}} \mathrm{NPs}$ together with their long-term stability, have shown the real potentiality of $\mathrm{Ru}$ in replacing $\mathrm{Pt}$ from WS electrochemical cells in the near future. However, while the carbon matrices where Ru NPs are embedded dramatically affect their catalytic behavior, they do not permit the easy tuning of their active sites, thus challenging the rational improvement of their catalytic performance through the establishment of structure-activity relationships.

\subsection{Supported electrochemical systems on metal/semimetal-based materials.}

Besides C-based supports, metal or semimetal-based materials such as $\mathrm{MoS}_{2},{ }^{[98]} \mathrm{MoO}_{2},{ }^{[99]} \mathrm{TiO}_{2},{ }^{[100]} \mathrm{W}^{[101]} \mathrm{Si},{ }^{[102]} \mathrm{Te},{ }^{[103]}$ $\mathrm{Y}(\mathrm{OH})_{3}{ }^{[104]}$ or $\mathrm{CeO}_{2}{ }^{[105]}$ have also been used as supports. For example, Qiao et al. described an extremely active catalyst in basic conditions $(1 \mathrm{M} \mathrm{KOH}) .{ }^{[98]}$ This system involves $10 \mathrm{~nm} \mathrm{Ru}$ NPs deposited onto $\mathrm{MoS}_{2}$ nanosheets lying onto carbon paper $\left(\mathrm{Ru} / \mathrm{MoS}_{2} / \mathrm{CP}\right)$ obtained by $\mathrm{Ru}(\mathrm{OH})_{3}$ calcination. It achieves $\eta_{0} \approx$ $0 \mathrm{mV}$ and $\eta_{10}=13 \mathrm{mV}$, and is totally stable for $12 \mathrm{~h}$ or 1000 cycles (Table 4, entry 22). Interestingly, the HER activity is significantly higher at basic $\mathrm{pH}$ than at acidic $\mathrm{pH}$. This results from the fact that at basic conditions the water dissociation process on $\mathrm{Ru}$ is coupled with the hydrogen atom adsorption on $\mathrm{MoS}_{2}$, thus providing a synergistic effect between the Ru NPs and the support. Also, a Ru- $\mathrm{MoO}_{2}$ composite made of Ru NPs anchored onto $600 \mathrm{~nm} \mathrm{MoO}$ particles (prepared by $\mathrm{RuCl}_{3}$ pyrolysis onto a suspension of a Mo-based metal organic framework) showed a very high HER activity at basic $\mathrm{pH}^{\left[{ }^{[99]} \text { This }\right.}$ catalyst surpassed the $\mathrm{Pt} / \mathrm{C}$ activity at $\mathrm{pH} 14$ with $\eta_{0}=0 \mathrm{mV}, \eta_{10}$ $=29 \mathrm{mV}$ and a Tafel slope $=31 \mathrm{mV} \cdot \mathrm{dec}^{-1}$ (Table 4, entry 23). From DFT calculations and XPS data, the authors propose that the combination of the weak $\mathrm{H}$ binding strength on $\mathrm{MoO}_{2}$ with the fast electron transfer between $\mathrm{Ru}$ and $\mathrm{MoO}_{2}$ might explain the enhanced HER activity of this nanocomposite both at basic and acidic $\mathrm{pH}$. Similarly, DFT data evidenced that the electronic interaction between $\mathrm{Ru}$ and $\mathrm{W}$ in a composite nanomaterial made of Ru NPs (2-5 nm) supported on carbon, dispersed into C Black and deposited onto W NPs $(60-80 \mathrm{~nm})$ by simple physical mixing $(\mathrm{W}+\mathrm{Ru} / \mathrm{C})$ led to a diminution of the $\mathrm{H}$ binding energy to $\mathrm{Ru}$, thus improving the HER efficiency at acidic $\mathrm{pH}$, reaching comparable activity and higher long-term stability than $\mathrm{Pt} / \mathrm{C}$ (Table 3, entry 24) ${ }^{[101]}$

Remarkably, Ru NPs have also been combined/alloyed with $\mathrm{Co},{ }^{[106,107]} \mathrm{Ni},{ }^{[108]} \mathrm{NiCo}{ }^{[109]}$ and $\mathrm{NiCoMo}^{[110]}$ nanostructures to form heterometallic electrocatalysts showing synergistic effects in HER similar to those above-mentioned for metal/semimetalbased supports. Thus, for example, Su, Yang and co-workers reported the doping of Co-based nanocubes with $3.58 \mathrm{wt} . \% \mathrm{Ru}$ followed by annealing at high temperature $\left(600{ }^{\circ} \mathrm{C}\right)$, which afforded $30 \mathrm{~nm}$ in size RuCo nanoalloys encapsulated into $\mathrm{N}$ doped graphene shells (RuCo@NC) of high activity $\left(\eta_{0} \approx 0 \mathrm{mV}\right.$, $\eta_{10}=28 \mathrm{mV}$, Tafel slope $=31 \mathrm{mV} \cdot \mathrm{dec}^{-1},\left|j_{0}\right|=3.31 \mathrm{~mA} \cdot \mathrm{cm}^{-2}$, Table 4, entry 20) and stability (increase of $\eta_{10}$ of only $4 \mathrm{mV}$ after 10000 cycles). ${ }^{[106]}$ According to DFT modelling, the presence of $\mathrm{Ru}$ increases the electron-transfer from the metallic core to the carbon shell, which lowers the $\mathrm{H}$ adsorption energy and increases the HER kinetics. Similarly, Dai and co-workers recently reported the combination of $\mathrm{Ru} N P s$ with $\mathrm{Ni@Ni} 2 \mathrm{P}$ nanorods (Ru-Ni@Ni ${ }_{2} \mathrm{P}-\mathrm{HNRs}$ ), which promoted, compared to the parent $\mathrm{Ni}_{2} \mathrm{P}$ system, faster $\mathrm{H}_{2}$ desorption (optimal $\mathrm{H}$ adsorption energy) and a faster electron-transfer, thus enhancing the HER kinetics of the system both at acidic and basic $\mathrm{pH}$ (Table 3, entry 28; Table 4, entry 29). ${ }^{[09]}$

In conclusion, the interaction of metallic $\mathrm{Ru}$ with other metal/semimetal-based nanostructures into mixed catalysts has been known to increase the HER catalytic activity compared to that of the respective separated systems as the result of a synergistic effect between both metals, which improves the electron conductivity and lowers the $\mathrm{H}$ adsorption energy.

\subsection{Photochemical systems.}

The inclusion of Ru NPs in HER photocatalytic systems is not an obvious task given the inherent difficulty in properly transferring electrons from a photosensitive molecule or material to the nanocatalyst while avoiding at the same time undesired backelectron transfer processes. Indeed, the electron transfer process between Ru NPs and the widely employed molecular photosensitizer $\left[\mathrm{Ru}(\mathrm{bpy})_{3}\right]^{2+}$ is generally not optimal. ${ }^{[111]}$ Thus, together with a sacrificial electron-donor (SED, e.g. NADH) supplying the needed electrons in half-cell systems, the use of an electron mediator (e.g. methyl viologen) is generally necessary. Only PSs attaining sufficient long-lived chargeseparated states after photoexcitation are able to inject electrons to the HER electrocatalyst without the need of using an electron mediator, thus making the systems less complex and more efficient.

In this regard, a molecular dyad that acts both as a PS and as an efficient electron supplier for Ru NPs has been described by Fukuzumi and co-workers, ${ }^{[112]}$ the 2-phenyl-4-(1-naphthyl)quinolinium ion (QuPh+-NA, see Scheme 1). Thus, they studied the photocatalytic HER using PVP-stabilized Ru NPs (PVP = polyvinylpyrrolidone) as catalyst and found optimal conditions for this system using the QuPh+-NA PS in alkaline solution. ${ }^{[112,113}$ 114] Two main conclusions can be extracted from their results. First, that there is no increase on the photocatalytic activity above a certain optimal catalyst concentration presumably due to light dispersion and opacity when more nanomaterial is present in the reaction medium. Second, that there is an activitysize dependency of the tested NPs. Small NPs present higher negative charge density, easing the proton reduction process but hindering the hydrogen-atom association step, since there is low density of $\mathrm{H}$ atoms on a single particle. Larger NPs ease the hydrogen-atom association step due to the presence of more $\mathrm{H}$ atoms on the NP surface, but hinder the previous proton reduction process as the negative charge density of the surface 
is initially lower. In consequence, the best results in their study were obtained with NPs of intermediate size, namely $4.1 \mathrm{~nm} .{ }^{[112]}$ Besides the QuPh+-NA ion, only the dye Eosin $\mathrm{Y}^{[115]}$ and the combination of $\left[\mathrm{Ru}(\mathrm{bpy})_{3}\right]^{2+}$ with 9-phenyl-10-methyl-acridinium derivatives as electron mediators ${ }^{[116]}$ have led to relative success in the photocatalytic HER with Ru-based NPs.

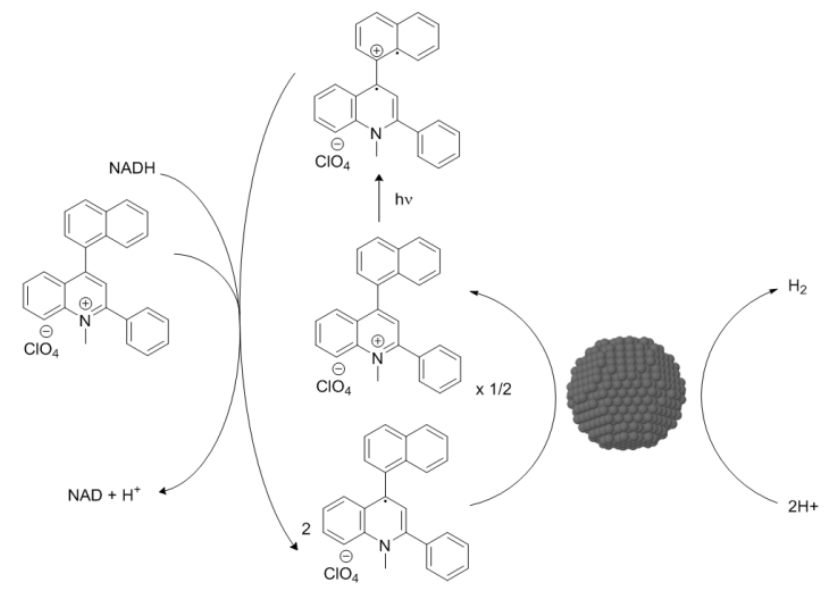

Scheme 1. Schematic representation of the electron transfer processes involved in photocatalytic hydrogen evolution promoted by Ru NPs in the presence of the QuPh ${ }^{+}$-NA organic donor-acceptor photoabsorber described by Fukuzumi et al. Adapted from ref. [112].

Still in the presence of QuPh+-NA as PS, the use of oxide-based materials $\left(\mathrm{SiO}_{2}, \mathrm{TiO}_{2}, \mathrm{CeO}_{2}\right.$, etc.) as supports for the Ru NPs led to less agglomeration under HER turnover conditions and, consequently, to enhanced photocatalytic stability with regards to the corresponding non-supported systems. ${ }^{[111]}$ In a similar direction but replacing the molecular PS by an organic bulk heterojunction layer able to absorb light and drive photoinduced exciton separation, organic photocathodes bearing $\mathrm{RuO}_{2} \mathrm{NPs}$ as catalytic centres yielded high photovoltages and photocurrent densities, as recently reported by Francàs, Durrant and coworkers. ${ }^{[117]}$ Finally, Ru NPs have been recently included as HER co-catalysts in tandem particle overall water splitting photocatalysts $\left(\mathrm{Ru}-\mathrm{SrTIO}_{3}: \mathrm{Ru} / \mathrm{BiVO}_{4}{ }^{[}{ }^{118} \quad\right]$ and doped derivatives $\left.{ }^{[119]}\right)$. Even if still at its infancy in terms of development, tandem particle-based photocatalysts are promising candidates with theoretically high limiting efficiency (ca. 28\%) and relatively low fabrication costs. 
Table 3. Comparison of the most relevant Ru-based HER nanoelectrocatalysts under acidic conditions. Parameters: mean diameter $(\varnothing)$, onset overpotential ( $\eta_{0}$, $\mathrm{mV})$, overpotential at $|j|=10 \mathrm{~mA} \cdot \mathrm{cm}^{-2}\left(\eta_{10}, \mathrm{mV}\right)$, Tafel slope $\left(\mathrm{b}, \mathrm{mV} \cdot \mathrm{dec}^{-1}\right)$, exchange current density $\left(|j \mathrm{j}|, \mathrm{mA} \cdot \mathrm{cm}^{-2}\right), \mathrm{specific} c \mathrm{current} \operatorname{density}\left(|j s|, \mathrm{mA} \cdot \mathrm{cm}{ }^{-2}\right)$ and turnover frequency $\left(\mathrm{TOF}, \mathrm{s}^{-1}\right)$. Unless otherwise stated, electrolyte is $0.5 \mathrm{M} \mathrm{H}_{2} \mathrm{SO}_{4}$.

\begin{tabular}{|c|c|c|c|c|c|c|c|c|c|}
\hline Entry & Catalyst & $\varnothing(n m)$ & $\eta_{0}(\mathrm{mV})$ & $\eta_{10}(\mathrm{mV})$ & $b\left(\mathrm{mV} \cdot \mathrm{dec}^{-1}\right)$ & $\left|j_{0}\right|\left(\mathrm{mA} \cdot \mathrm{cm}^{-2}\right)$ & $\begin{array}{ll}|j s| & \left(\mathrm{mA}^{\prime} \cdot \mathrm{cm}^{-}\right. \\
2) & \end{array}$ & $\operatorname{TOF}\left(\mathrm{s}^{-1}\right)$ & Ref. \\
\hline 1 & $\mathrm{RuO}_{2}-\mathrm{C}$ (Vulcan) & $5-8$ & $\approx 0$ & $\approx 15$ & 26 & - & 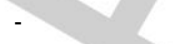 & - & 64 \\
\hline 2 & $\begin{array}{l}\text { GCE-S-GNs-1000- } \\
\text { CB-Ru }\end{array}$ & 30 & $\approx 60$ & 80 & $\begin{array}{l}61 \text { (Tafel) } \\
71 \text { (EIS) }\end{array}$ & $\begin{array}{l}0.541 \\
0.431\end{array}$ & 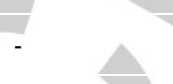 & & 69 \\
\hline 3 & Ru-GC & 100 & 10 & 90 & $\approx 33$ & - & - & - & 71 \\
\hline 4 & Ru-GLC & $2-5$ & 3 & 35 & 46 & 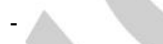 & - & - & 83 \\
\hline 5 & $\mathrm{RuO}_{2}-\mathrm{NWs@g-CN}$ & $10-40$ & 14 & 93 & 40 & 0.22 & - & - & 38 \\
\hline 6 & $\mathrm{Ru} / \mathrm{g}-\mathrm{C}_{3} \mathrm{~N}_{4} / \mathrm{C}$ & 2 & $\approx 15-20$ & $\approx 70$ & - & - & - & $\approx 4.85(100 \mathrm{mV})$ & 88 \\
\hline 7 & $\mathrm{Ru} @ \mathrm{C}_{2} \mathrm{~N}$ & 1.6 & 9.5 & $\begin{array}{l}22 \text { (13.5 after } \\
1000 \text { cycles) }\end{array}$ & 30 & 1.9 & - & $\begin{array}{l}0.67(25 \mathrm{mV}) \\
1.95(50 \mathrm{mV})\end{array}$ & 15 \\
\hline 8 & Ru-CCS & $3.25 \pm 0.73$ & 11.0 & 27.3 & 33 & & - & $3.70(50 \mathrm{mV})$ & 90 \\
\hline 9 & RuPx@NPC & 4 & 25 & 51 & 46 & - & - & - & 92 \\
\hline 10 & $\mathrm{RuP} / \mathrm{C}$ & 32 & $\approx 0$ & 19 & 37 & 3.22 & - & $3.35(20 \mathrm{mV})$ & 97 \\
\hline 11 & $\mathrm{Ru}_{2} \mathrm{P} / \mathrm{RGO}$ & $<7$ & $\approx 0$ & 22 & 29 & 2.2 & - & - & 94 \\
\hline 12 & Ru 2 P@PNC/CC-900 & $\begin{array}{l}20.19 \quad \pm \\
9.62\end{array}$ & $\approx 0$ & 15 & 28 & - & - & - & 95 \\
\hline 13 & RuP2@NPC & 8 & $\approx 0$ & 38 & 38 & 1.99 & - & - & 93 \\
\hline 14 & Ru@CN & 2.37 & $\approx 70$ & 126 & - & - & - & - & 84 \\
\hline 15 & Ru-NGC & $\approx 5$ & 9.5 & 25 & 31 & - & - & $0.68(30 \mathrm{mV})$ & 79 \\
\hline 16 & Ru@GnP & 2 & $\approx 0$ & 13 & 30 & - & - & $0.26(100 \mathrm{mV})$ & 81 \\
\hline 17 & Ru-HPC & 2.87 & $\approx 15$ & 61.6 & 66.8 & 1.2 & - & $0.18(25 \mathrm{mV})$ & 40 \\
\hline 18 & $\mathrm{Ru} / \mathrm{CeO}_{2}$ & $3.89 \pm 1.24$ & 33 & 47 & 41 & 0.67 & - & $0.8(27 \mathrm{mV})$ & 105 \\
\hline 19 & $\begin{array}{l}\text { Ru-GC } \\
\text { (Ru-MeOH/THF) }\end{array}$ & & 0 & 83 & 46 & - & $\begin{array}{l}0.36 \\
\mathrm{mV})\end{array}$ & $\begin{array}{l}0.07(25 \mathrm{mV}) \\
0.10(50 \mathrm{mV}) \\
0.87(100 \mathrm{mV})\end{array}$ & 73 \\
\hline 20 & $\mathrm{Ru} / \mathrm{MoS}_{2} / \mathrm{CP}$ & 10 & $\approx 60$ & 96 & - & - & - & - & 98 \\
\hline 21 & $\mathrm{Ru}-\mathrm{MoO}_{2}$ & & $\approx 0$ & 55 & 44 & - & - & - & 99 \\
\hline 22 & $\mathrm{Ru}(0) / \mathrm{TiO}_{2}$ & $4.7 \pm 1.2$ & 34 & 41 & 52 & 0.728 & - & - & 100 \\
\hline 23 & $\mathrm{Ni}_{1.5} \mathrm{Co}_{1.4} \mathrm{P} @ \mathrm{Ru}$ & 4 & $\approx 0$ & 49 & 49 & 1.26 & - & - & 108 \\
\hline 24 & $\mathrm{~W}+\mathrm{Ru} / \mathrm{C}$ & $2-5$ & $\approx 45$ & 85 & 46 & 0.049 & - & - & 101 \\
\hline
\end{tabular}




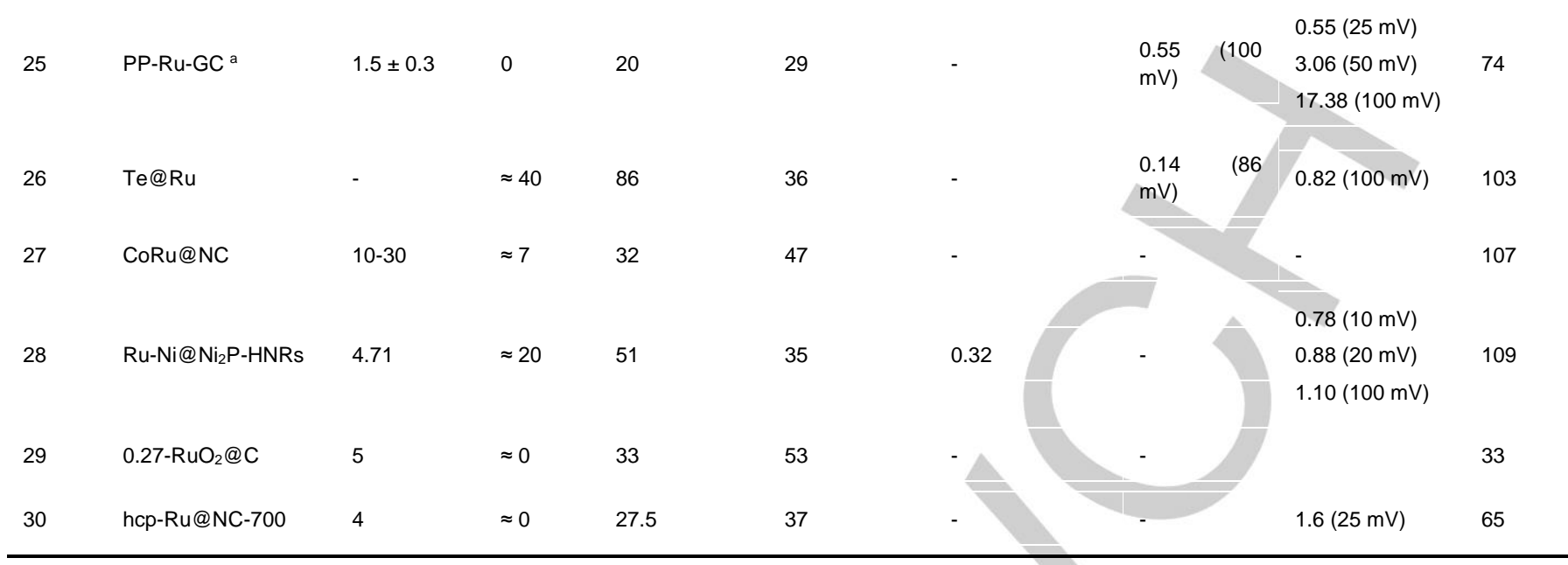

Electrolyte: [a] $1 \mathrm{M} \mathrm{H}_{2} \mathrm{SO}_{4}$.

Table 4. Comparison of the most relevant Ru-based HER nanoelectrocatalysts under basic conditions. Parameters: mean diameter ( $\varnothing$ ), onset overpotential ( $\eta_{0}$, $\mathrm{mV})$, overpotential at $|j|=10 \mathrm{~mA} \cdot \mathrm{cm}^{-2}\left(\eta_{10}, \mathrm{mV}\right)$, Tafel slope $\left(\mathrm{b}, \mathrm{mV} \cdot \mathrm{dec}^{-1}\right)$, exchange current density $\left(|j o|, \mathrm{mA} \cdot \mathrm{cm}^{-2}\right), \mathrm{specific} c u r r e n t \operatorname{density~}\left(|j s|, \mathrm{mA} \cdot \mathrm{cm} \mathrm{m}^{-2}\right)$ and turnover frequency $\left(\mathrm{TOF}, \mathrm{s}^{-1}\right)$. Unless otherwise stated, electrolyte is $1.0 \mathrm{M} \mathrm{KOH} / \mathrm{NaOH}$.

\begin{tabular}{|c|c|c|c|c|c|c|c|c|c|}
\hline Entry & Catalyst & $\varnothing(\mathrm{nm})$ & $\eta_{0}(\mathrm{mV})$ & $\eta_{10}(\mathrm{mV})$ & $b\left(\mathrm{mV} \cdot \mathrm{dec}^{-1}\right)$ & $\left|j_{0}\right|\left(\mathrm{mA} \cdot \mathrm{cm}^{-2}\right)$ & $|j \mathrm{~s}|\left(\mathrm{mA} \cdot \mathrm{cm}^{-2}\right)$ & TOF $\left(\mathrm{s}^{-1}\right)$ & Ref. \\
\hline 1 & RuO $2-N W s @ g-C N$ b & $10-40$ & 16 & 95 & 70 & 0.28 & - & - & 38 \\
\hline 2 & $\mathrm{Ru} @ \mathrm{C}_{2} \mathrm{~N}$ & 1.6 & - & 17 & 38 & & - & $\begin{array}{l}0.76(25 \mathrm{mV}) \\
1.66(50 \mathrm{mV})\end{array}$ & 15 \\
\hline 3 & hydrous $-\mathrm{RuO}_{2}$ & $<5$ & $\approx 25$ & 60 & - & - & - & - & 29 \\
\hline 4 & crystalline- $\mathrm{RuO}_{2}$ & - & $\approx 25$ & 74 & & - & - & - & 29 \\
\hline 5 & $\mathrm{Ru} / \mathrm{g}-\mathrm{C}_{3} \mathrm{~N}_{4} / \mathrm{C}^{\mathrm{a}}$ & 2 & $\approx 15-20$ & 79 & - & 0.46 & - & $4.2(100 \mathrm{mV})$ & 88 \\
\hline 6 & Ru/NG-750 & $5.8 \pm 1.5$ & 0 & 8 & 30 & - & - & $0.35(100 \mathrm{mV})$ & 66 \\
\hline 7 & RuPx@NPC & 4 & $\approx 30$ & 74 & 70 & - & - & - & 92 \\
\hline 8 & $\mathrm{RuP} / \mathrm{C}$ & 32 & $\approx 0$ & 18 & 34 & 3.07 & - & $3.62(20 \mathrm{mV})$ & 97 \\
\hline 9 & $\mathrm{Ru}_{2} \mathrm{P} / \mathrm{RGO}$ & $<7$ & $\approx 0$ & 13 & 56 & - & - & - & 94 \\
\hline 10 & $\mathrm{Ru}_{2} \mathrm{P} @ \mathrm{PNC} / \mathrm{CC}-900$ & $\begin{array}{l}20.19 \\
9.62\end{array}$ & $\approx 25$ & 50 & 66 & - & - & - & 95 \\
\hline 11 & RuP $2 @ N P C$ & 8 & $\approx 0$ & 52 & 69 & - & - & - & 93 \\
\hline 12 & Ru@CN & 2.37 & $\approx 0$ & 32 & 53 & - & - & - & 84 \\
\hline 13 & Ru@NC & 1.6 & 15 & 26 & 36 & - & - & $\begin{array}{l}0.83(25 \mathrm{mV}) \\
3.02(50 \mathrm{mV}) \\
10.8(100 \mathrm{mV})\end{array}$ & 82 \\
\hline 14 & $\mathrm{Ru} / \mathrm{CN}-800$ & $\approx 1.3$ & $\approx 0$ & 14 & 30.0 & - & - & - & 77 \\
\hline 15 & Ru/3DNPC-500 & 1.32 & $\approx 0$ & 15 & 31 & - & - & - & 78 \\
\hline
\end{tabular}




\begin{tabular}{|c|c|c|c|c|c|c|c|c|c|}
\hline 16 & Ru-NGC & $\approx 5$ & $\approx 12.5$ & $\approx 37$ & 40 & - & - & - & 79 \\
\hline 17 & CN $@$ @Ru/MWCNT & $6.0 \pm 2.3$ & 20 & 39 & 28 & - & - & & 80 \\
\hline 18 & Ru@GnP & 2 & $\approx 0$ & 22 & 28 & - & - & $(100 \mathrm{mV})$ & 81 \\
\hline 19 & Ru-HPC & 2.87 & $\approx 0$ & $\approx 5$ & 33.9 & 6.59 & & $79(25 \mathrm{mV})$ & 40 \\
\hline 20 & RuCo@NC & 30 & $\approx 0$ & 28 & 31 & 3.31 & & & 106 \\
\hline 21 & CoRu@NC & $10-30$ & $\approx 20$ & 45 & 66 & - & - & - & 107 \\
\hline 22 & $\mathrm{Ru} / \mathrm{MoS}_{2} / \mathrm{CP}$ & 10 & $\approx 0$ & 13 & 60 & - & $0.075(50 \mathrm{mV})$ & - & 98 \\
\hline 23 & $\mathrm{Ru}-\mathrm{MoO}_{2}$ & - & 0 & 29 & 31 & - & & - & 99 \\
\hline 24 & $\mathrm{Ni}_{1.5} \mathrm{Co}_{1.4} \mathrm{P} @ \mathrm{Ru}$ & 4 & $\approx 12$ & 52 & 50 & - & & - & 108 \\
\hline 25 & $\mathrm{Ru} / \mathrm{C}-300$ & 1.48 & $\approx 0$ & 14 & 32.5 & - & & - & 67 \\
\hline 26 & $\mathrm{PP}-\mathrm{Ru} / \mathrm{RuO}_{2}-\mathrm{GC}$ & $1.5 \pm 0.3$ & 0 & 25 & 65 & - & $0.19(100 \mathrm{mV})$ & - & 74 \\
\hline 27 & $\mathrm{Ru} / \mathrm{C}$ & $1.73 \pm 0.47$ & $\approx 0$ & 24 & 33 & - & - & $0.18(40 \mathrm{mV})$ & 76 \\
\hline 28 & $\begin{array}{l}\text { Cu-doped Ru- } \\
\mathrm{RuO}_{2} / \mathrm{C}\end{array}$ & $2.5-4.5$ & $\approx 15$ & 28 & 35 & - & - & - & 47 \\
\hline 29 & Ru-Ni@Ni2P-HNRs & 4.71 & $\approx 5$ & 31 & 41 & - & - & - & 109 \\
\hline 30 & NiCoMo/Ru-GN a & - & $\approx 0$ & 11.4 & 38 & 6.31 & - & - & 110 \\
\hline 31 & 0.27-RuO & 5 & $\approx 0$ & 20 & 46 & - & - & - & 33 \\
\hline 32 & ah-RuO2@C & 150 & $\approx 20$ & 63 & 62 & - & - & - & 33 \\
\hline
\end{tabular}

Electrolyte: [a] $0.1 \mathrm{M} \mathrm{KOH}$ and [b] $0.5 \mathrm{M} \mathrm{KOH}$. 


\section{Bifunctional $\mathrm{Ru} / \mathrm{RuO}_{2}$ systems and their use in WS electrolytic cells}

As noted above in Sections 3 and 4, Ru-based nanoparticulated materials are good candidates for acting either as anodes (OER) or as cathodes (HER) in WS electrocatalytic cells. Furthermore, some studies have revealed the ability of Ru NPs to act both as OER and HER electrocatalysts, thus becoming real bifunctional catalysts after a slight modification of their structure/oxidation state or even without any further change. This section accounts on such bifunctional electrocatalysts and, when reported, on their implementation in overall WS electrolytic cells.

Given the instability (corrosion) of metallic Ru NPs under OER conditions $^{[31]}$ (typically overoxidized to molecular $\mathrm{RuO}_{4}$, see Section 3.1 above), bifunctional Ru-based nanoparticulated systems are typically $\mathrm{RuO}_{2}$ or $\mathrm{Ru} / \mathrm{RuO}_{2}$ mixtures. Besides catalyzing the OER, $\mathrm{RuO}_{2}$ has also been reported as a HER electrocatalyst. As established by recent works, ${ }^{[63,74]}$ this suggests a change of the oxidation state at its surface due to the reductive conditions applied (see Section 4.1 above), which may favor the formation of a Ru-H bond. However, the evolution of the $\mathrm{Ru}$ oxidation state at the surface of the NPs under HER conditions is not always monitored, and the reports only consider the original composition of the catalyst.

A first set of Ru-based electrolyzers for the whole WS deals with the use of $\mathrm{RuO}_{2} \mathrm{NPs}$ both in the anode and in the cathode. For instance, Lim and co-workers reported a hydrous/crystalline $\mathrm{RuO}_{2}$ bifunctional electrocatalyst and its integration in an efficient cell for the overall splitting of water. These authors reported the combination of a cathode made of stable hydrous $\mathrm{RuO}_{2} \mathrm{NPs} / \mathrm{Ni}$ foam (Table 4, entry 3 ) with a crystalline- $\mathrm{RuO}_{2} / \mathrm{Ni}$ foam anode obtained by annealing the former hydrous species (Table 2, entry 3). This combination of electrodes afforded an efficient alkaline electrolyzer, achieving an overall $\eta_{0} \approx 170 \mathrm{mV}$ and $\eta_{10}=273 \mathrm{mV}$, values that outperform those obtained with $(\mathrm{Pt} / \mathrm{C}) / \mathrm{Ni}$ and $\mathrm{IrO}_{2} / \mathrm{Ni}$ as cathodic and anodic electrode materials, respectively. ${ }^{[29]}$ In a related example, Jang, Song and coworkers recently described the use of partially hydrous $\mathrm{RuO}_{2}$ NPs embedded in a C matrix as a multifunctional electrocatalyst, ${ }^{[33]}$ being the HER (Table 3, entry 29; Table 4, entry 31 ) and the OER (Table 1, entry 7; Table 2, entry 8) two of its functionalities (see Sections 3 and 4 for more details). When used both as cathode and anode in a WS electrocatalytic cell at $\mathrm{pH} 14$, this nanomaterial yields and overall $\eta_{10}$ of $280 \mathrm{mV}$. This result also highlights the potential of the alternating operation mode of their electrolyzer by switching the employed HER/OER electrodes, thus demonstrating a superior durability of the system since long-term exposure to oxidative (or reductive) environments is avoided. Also, Barman et al. published a bifunctional catalyst made of crystalline rutile $\mathrm{RuO}_{2}$-nanowires (100-200 nm in length and 10-40 nm in diameter) supported onto carbon nitride $\left(\mathrm{RuO}_{2}-\mathrm{NWs@g-CN}\right),{ }^{[38]}$ able to catalyze both the OER (Table 1, entry 3; Table 2, entry 4) and the HER (Table 3 , entry 5; Table 4, entry 1 ) with good-to-moderate activities and high stabilities at acidic and basic $\mathrm{pH}$. Moreover, when used in both the cathode and the anode of a WS electrolytic cell at $\mathrm{pH}$ 14 this nanomaterial afforded an overall $\eta_{0} \approx 100 \mathrm{mV}$ and $\eta_{10}=$ $300 \mathrm{mV}$.

A second set of Ru-based WS electrolyzers are those combining metallic $\mathrm{Ru}$ and $\mathrm{RuO}_{2}$ either as pure or as mixed electrode materials. Thus, Chen and co-workers have recently described the bifunctional catalytic character of a Cu-doped $\mathrm{Ru}-\mathrm{RuO}_{2} / \mathrm{C}$ composite (Table 2, entry 5; Table 4 , entry 28), ${ }^{[4]}$ in which a mixture of 2.5-4.5 nm fcc and hcp-Ru NPs and rutile-RuO $\mathrm{O}_{2} \mathrm{NPs}$ doped with $\mathrm{Cu}$ are embedded in a $\mathrm{C}$ matrix. They assigned the HER activity of the material to the Ru NPs, and the OER one to the $\mathrm{RuO}_{2} \mathrm{NPs}$. When using this composite material in both the cathode and the anode of a WS electrolytic cell at pH 14 an overall $\eta_{10}$ of $240 \mathrm{mV}$ is achieved. Finally, a second relevant example of such a type of electrolyzers has been recently reported by Zou and co-workers ${ }^{[40]}$ arising from the combination of their Ru-HPC/P-RuO 2 hierarchical cathodic/anodic materials (see Sections 3.3.1 and 4.2 for the description of the individual performance in OER and HER, respectively) that originate from the pyrolytic decomposition of a CuRu-MOF. The two-electrode WS device operates at an overall $\eta_{10}$ of $300 \mathrm{mV}$ in $1.0 \mathrm{M} \mathrm{KOH}$ and shows excellent long-term ( $24 \mathrm{~h}$ ) stability at a cell voltage of $1.65 \mathrm{~V}$

\section{Conclusions and Challenges}

In the last decade Ru-based NPs have clearly emerged as practical (electro)catalytic systems for the two half-cell reactions in water splitting. In this regard, benchmarking methodologies, which have become widespread along the same period, have objectively shown the comparable or occasionally even superior performance of Ru-based NP systems to the standard Pt and $\mathrm{IrO}_{\mathrm{x}}$ species used for catalyzing the HER and the OER in commercial electrolyzers, respectively. At the same time, the fair comparison of catalysts through benchmarking strategies has also allowed to identify the main drawbacks characterizing these systems.

A quick glance at the primary figures of merit for the most representative HER and OER electrocatalysts (particularly $\eta_{10}$, Tafel slope (b) and TOF per real active site) highlights the divergence in mechanistic complexity of the two half-reactions. Thus, HER systems show clearly faster kinetics (TOFs about one order of magnitude higher, compare Figures 3 and 6) and attain practical current densities $\left(\eta_{10}\right)$ at much lower overpotentials (below $100 \mathrm{mV}$ for the HER, Figure 5, and above $200 \mathrm{mV}$ for the OER, Figure 2).

OER catalysts work in harsh oxidative conditions that usually compromise their stability. This is the case of metallic Ru NPs (and certain $\mathrm{Ru} / \mathrm{RuO}_{2}$ mixtures), which tend to over-oxidize to the soluble and volatile $\mathrm{RuO}_{4}$ form under turnover conditions. Though, pure $\mathrm{RuO}_{2}$ or core-shell systems where a Ru shell is combined with a more noble metal core tend to be more stable. Thus, even if the main activity-related figures of merit for Rubased nanoparticulated OER electrocatalysts (see Tables 1 and 2) are comparable to those of the state-of-the-art $\mathrm{IrO}_{x}$ species, strategies to rationally improve their long-term stability must be 
further developed. Together, the influence of the degree of crystallinity of the nanocatalysts both in terms of activity and stability is another unclear matter, currently with non-conclusive and even contradictory reports. Also, supported Ru NP-based OER systems are relatively scarce and have been mainly developed with $\mathrm{SiO}_{2}$ materials of different porosity and pore size while triggered both chemically and/or photochemically. Together with the general effect of the support preventing NP aggregation under turnover conditions and thus improving the catalyst durability, pores large enough to ensure both the proper exposure of the NP active sites and the correct diffusion of the oxidants/photoabsorbers used have proven to be a key feature of these systems. All in all, the establishment of structureactivity/stability relationships remains as the main challenge in the OER field when employing Ru NPs as catalysts. In this regard, the combination of advanced (and operando) NP surface characterization techniques and computational modelling appears as a promising track still almost unexplored today.

As stated in Section 4, the development of Ru-based NPs as catalysts for the HER is a dynamic field of research where many advances have been made in the last three years. Contrary to the OER, the majority of Ru-based NPs systems reported for the HER are electrocatalysts that have been benchmarked through the typical figures of merit discussed in Section 2 (see Tables 3 and 4) and their mechanistic pathways have been related to structural/electronic features of the NPs or NP-based hybrids by combining both experimental and theoretical DFT calculations. As stated above, the distinction between "non-supported" (Section 4.1) and "supported" (Section 4.2) systems is of interest. The formers are simpler systems where the active sites of the NPs can be tuned with ease and the surface chemistry resembles somehow that of molecular complexes. In this regard, the organometallic approach for the synthesis of nanostructures (see above) opens a myriad of possibilities by means of the inexhaustible ligand pool of NP stabilizers. The combination of electrochemical analysis, detailed structural and surface characterization and DFT modelling of the involved reaction pathways can lead to structure-activity/stability relationships,

\section{Acknowledgements}

Sustained support from MINECO, FEDER, AGAUR, CNRS, the University Paul Sabatier - Toulouse and the GDRI HC3A Franco-Catalan action are gratefully acknowledged. Recent research projects and grants include CTQ2011-26440, CTQ2015-64261-R, IDEX UNITI Emergence project (UFTMIP: 2015-209-CIF-D-DRD-127185), CTP2013-0016 and MidiPyrénées $/ \mathrm{n}^{\circ} 13053026$. J.C. thanks the UAB and the "Euroregió Pirineus Mediterrànea" for predoctoral grants. J. De T. acknowledges the UAB for a PIF predoctoral grant. J.G.-A. acknowledges the Serra Húnter Program.

Keywords: ruthenium $\cdot$ nanoparticle $\cdot$ hydrogen evolution reaction $\cdot$ oxygen evolution reaction $\cdot$ electrocatalysis thus allowing the subsequent rational improvement of the electrocatalytic HER systems. In contrast, the "supported" systems are more complex hybrid or composite materials of difficult tunability, where the interaction of the Ru NPs with the typically carbon-based support/matrix results on increased stability (aggregation is prevented) and, in some cases, on particularly interesting catalytic properties arising from the support/matrix influence on the catalysts structure. Thus, for instance, these systems have shown appropriate $\mathrm{H} / \mathrm{H}_{2} \mathrm{O}$ adsorption energies and $\mathrm{H}_{2} \mathrm{O}$ dissociation rates in alkaline solution (especially when $\mathrm{Ru}$ adopts its uncommon fcc-phase) that, together with their long-term stability at this $\mathrm{pH}$, have raised Ru-based nanoparticulated electrocatalysts as plausible candidates to replace Pt in cathodes for practical WS. However, most of the above-mentioned systems are complex and/or of difficult scalability, and very few have been triggered by light. Thus, the development of simple, scalable and cost-effective HER electrocatalytic systems based on Ru NPs and their triggering by sunlight in combination with molecular or semiconducting photoabsorbers are two of the main challenges the field will face in the upcoming years.

The deep mechanistic understanding attained in the last decade for Ru molecular complexes can also serve as a reservoir of inspiration to develop improved HER and OER nanomaterials. Thus, the potential benefits of transferring key molecular concepts such as, for instance, the kinetic effects of internal bases, the redox-activity of capping molecules/ligands or the fine-tuning of redox potentials should be carefully assessed. Again, combination of experimental and computational analyses will be imperative in this complex endeavor.

Finally, a very encouraging field has been opened lately with the use of real bifunctional HER/OER Ru-based NPs. Thus, as stated in Section 5, the use of either $\mathrm{RuO}_{2}$ or the combination of metallic $\mathrm{Ru}$ and $\mathrm{RuO}_{2}$, either as pure or as mixed electrode materials, has been reported and, even more importantly, these materials have been successfully incorporated into compact water splitting electrocatalytic cells. 


\section{Entry for the Table of Contents}

\section{REVIEW}

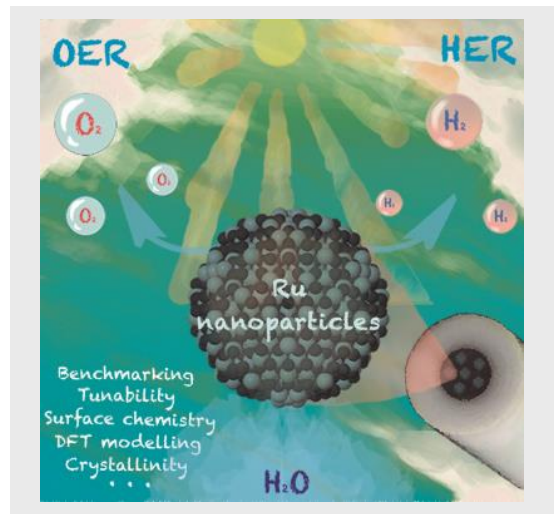

HER and OER catalysts are key components for obtaining new sustainable energy conversion schemes based on water splitting and sunlight. This review covers the most significant developments on Ru-based nanoparticles as catalysts for these processes, focusing on the factors governing their performance.
J. Creus, J. De Tovar, N. Romero, J. García-Antón, K. Philippot*, R. Bofill*, and X. Sala*

Page No. - Page No.

Ruthenium Nanoparticles for Catalytic Water Splitting 
[1] L. N. Lewis, Science 2016, 351, 6271

[2] C. Amiens, B. Chaudret, D. Ciuculescu-Pradines, V. Collière, K. Fajerwerg, P. Fau, M. Kahn, A. Maisonnat, K. Philippot, New J. Chem. 2013, 37, 3374-3401.

[3] C. J. Murphy, J. M. Buriak, Chem. Mater. 2015, 27, 4911-4913.

[4] C. C. L. McCrory, S. Jung, J. C. Peters, T. F. Jaramillo, J. Am. Chem. Soc. 2013, 135, 16977-16987.

[5] A. Harriman, I. J. Pickering, J. M. Thomas, P. A. Christensen, J. Chem Soc., Faraday Trans. 1 1988, 84, 2795-2806.

[6] H. Over, Chem. Rev. 2012, 112, 3356-3426.

[7] I. C. Man, H.-Y. Su, F. Calle-Vallejo, H. A. Hansen, J. I. Martínez, N. G. Inoglu, J. Kitchin, T. F. Jaramillo, J. K. Nørskov, J. Rossmeisl ChemCatChem 2011, 3, 1159-1165.

[8] E. A. Paoli, F. Masini, R. Frydenal, D. Deiana, C. Schlaup, M. Malizia, T. W. Hansen, S. Horch, I. E. L. Stephens, I. Chorkendorff, Chem. Sci. 2015, 6, 190-196.

[9] X. Sala, S. Maji, R. Bofill, J. García-Antón, L. Escriche, A. Llobet, Acc. Chem. Res. 2014, 47, 504-516

[10] R. Matheu, M. Z. Ertem, J. Benet-Buchholz, E. Coronado, V. S. Batista, X. Sala, A. Llobet, J. Am. Chem. Soc. 2015, 137, 10786-10795.

[11] P. Garrido-Barros, C. Gimbert-Suriñach, R. Matheu, X. Sala, A. Llobet, Chem. Soc. Rev. 2017, 46, 6088-6098.

[12] R. Matheu, L. Francàs, P. Chernev, M. Z. Ertem, V. Batista, M. Haumann, X. Sala, A. Llobet, ACS Catal. 2015, 5, 3422-3429.

[13] J. K. Nørskov, T. Bligaard, A. Logadottir, J. R. Kitchin, J. G. Chen, S Pandelov, U. Stimming, J. Electrochem. Soc. 2005, 152, J23-J26.

[14] Y. Zheng, Y. Jiao, M. Jaroniec, S.Z. Qiao, Angew. Chem. Int. Ed. 2015 $54,52-65$

[15] J. Mahmood, F. Li, S. Jung, M. S. Okyay, I. Ahmad, S. Kim, N. Park, H. Y. Jeong, J. Baek, Nature Nanotech. 2017, 12, 441-446.

[16] C. C. L. McCrory, S. Jung, I. M. Ferrer, S. M. Chatman, J. C. Peters, T. F. Jaramillo, J. Am. Chem. Soc. 2015, 137, 4347-4357.

[17] M. P. Browne, C. O'Rourke, N. Wells, A. Mills, ChemPhotoChem 2018 2, 293-299.

[18] M. P. Browne, C. O’Rourke, A. Mills, Electrochem. Commun. 2017, 85, 1-5.

[19] S. Anantharaj, S. R. Ede, K. Karthick, S. S. Sankar, K. Sangeetha, P. E. Karthik, S. Kundu, Energy Environ. Sci. 2018, 11, 744-771.

[20] S. Jung, C. C. L. McCrory, I. M. Ferrer, J. C. Peters, T. F. Jaramillo, J. Mater. Chem. A 2016, 4, 3068-3076.

[21] C. Spöri, J. T. H. Kwan, A. Bonakdarpour, D. P. Wilkinson, P. Strasser Angew. Chem. Int. Ed. 2017, 56, 5994-6021.

[22] C. Wei, R. R. Rao, J. Peng, B. Huang, I. E. L. Stephens, M. Risch, Z. J. Xu, Y. Shao-Horn, Adv. Mater. 2019, 1806296.

[23] R. L. Doyle, I. J. Godwin, M. P. Brandon, M. E. G. Lyons, Phys. Chem. Chem. Phys. 2013, 15, 13737-13783.

[24] C. L. Gree, A. Kucernak, J. Phys. Chem. B 2002, 106, 1036-1047.

[25] T. Shinagawa, A. T. Garcia-Esparza, K. Takanabe, Sci. Rep. 2015 5:13801.

[26] S. Fletcher, J. Solid State Electrochem. 2009, 13, 537-549.

[27] T. Shinagawa, A. T. Garcia-Esparza, K. Takanabe, Sci. Rep. 2015, 5 Article ํㅡ 13801; B. E. Conway, B. V. Tilak, Electrochim. Acta 2002, 47 3571-3594.

[28] M. Zeng, Y. Li, J. Mater. Chem. A 2015, 3, 14942-14962.

[29] J. Lee, S. A. S. Shah, P. J. Yoo, B. Lim, Chem. Phys. Lett. 2017, 673, 89-92.

[30] K. Maeda, R. Abe, K. Domen, J. Phys. Chem. C 2011, 115, 3057-3064.

[31] T. Reier, M. Oezaslan, P. Strasser, ACS Catal. 2012, 2, 1765-1772.

[32] Y. Zhang, T. Ren, Chem. Commun. 2012, 48, 11005-11007.

[33] H.-S. Park, J. Yang, M. K. Cho, Y. Lee, S. Cho, S.-D. Yim, B.-S. Kim, J. H. Jang, H.-K. Song, Nano Energy 2019, 55, 49-58.

[34] E. S. Gnanakumar, W. Ng, B. C. Filiz, G. Rothenberg, S. Wang, H. Xu, L. Pastor-Pérez, M. M. Pastor-Blas, A. Sepúlveda-Escribano, N. Yan, N. R. Shiju, ChemCatChem 2017, 9, 4159-4163.
[35] J. Xu, S. Murphy, D. Xiong, R. Cai, X.-K. Wei, M. Heggen, E. Barborini, S. Vinati, R. E. Dunin-Borkowski, R. E. Palmer, ACS Appl. Energy Mater. 2018, 1, 3013-3018

[36] S. Y. Tee, C. J. J. Lee, S. S. Dinachali, S. C. Lai, E. L. Williams, H.-K Luo, D. Chi, T. S. A. Hor, M.-Y. Han, Nanotechnology 2015, 26 415401-415407.

[37] Y. Lee, J. Suntivich, K. J. May, E. E. Perry, Y. Shao-Horn, J. Phys. Chem. Lett. 2012, 3, 399-404.

[38] T. Bhowmik, M. K. Kundu, S. Barman, ACS Appl. Mater. Interfaces 2016, 8, 28678-28688.

[39] X. Kong, K. Xu, C. Zhang, J. Dai, S. N. Oliaee, L. Li, X. Zeng, C. Wu, Z Peng, ACS Catal. 2016, 6, 1487-1492.

[40] T. Qiu, Z. Liang, W. Guo, S. Gao, C. Qu, H. Tabassum, H. Zhang, B. Zhu, R. Zou, Y. Shao-Horn, Nano Energy 2019, 58, 1-10.

[41] K. P. J. Gustafson, A. Shatskiy, O. Verho, M. D. Kärkäs, B. Schluschass, C. Tai, B. Åkermark, J. Bäckvall, E. V. Johnston, Catal. Sci. Technol. 2017, 7, 293-299.

[42] K. Okeyoshi, R. Yoshida, Adv. Funct. Mater. 2010, 20, 708-714.

[43] H. Yoo, Y. Choi, J. Choi, ChemCatChem 2015, 7, 643-647.

[44] A. Mills, P. A. Duckmanton, J. Reglinski, Chem. Commun. 2010, 46 2397-2398.

[45] S. Stucki, A. Menth, Ber. Bunsen-Ges. 1980, 84, 1008-1013

[46] K. A. Stoerzinger, L. Qiao, M. D. Biegalski, Y. Shao-Horn, J. Phys. Chem. Lett. 2014, 5, 1636-1641.

[47] K. Yang, P. Xu, Z. Lin, Y. Pang, P. Jiang, C. Wang, S. Liu, S. Gong, L. Hu, Q. Chen, Small DOI: 10.1002/smll.201803009.

[48] L. Wang, Q. Zhou, Z. Pu, Q. Zhang, X. Mu, H. Jing, S. Liu, C. Chen, S. Mu, Nano Energy 2018, 53, 270-276.

[49] E. Tsuji, A. Imanishi, F. Fukui, Y. Nakato, Electrochimica Acta 2011, 56 2009-2016.

[50] R. Kötz, H. J. Lewerenz, S. Stucki, J. Electrochem.Soc. 1983, 130, 825 829.

[51] L. Gloag, T. M. Benedetti, S. Cheong, R. F. Webster, C. E. Marjo, J. J. Gooding, R. D. Tilley, Nanoscale 2018, 10, 15173-15177.

[52] L. Gloag, T. M. Benedetti, S. Cheong, C. E. Marjo, J. J. Gooding, R. D. Tilley, J. Am. Chem. Soc. 2018, 140, 12760-12764.

[53] L. Gloag, T. M. Benedetti, S. Cheong, Y. Li, X.-H. Chan, L.-M. Lacroix S. L. Y. Chang, R. Arenal, I. Florea, H. Barron, A. S. Barnard, A. M Henning, C. Zhao, W. Schumann, J. J. Gooding, R. D. Tilley, Angew. Chem. Int. Ed. 2018, 57, 10241-10245.

[54] L. Francàs, X. Sala, J. Benet-Buchholz, L. Escriche, A. Llobet, ChemSusChem 2009, 2, 321-329.

[55] A. C. Sander, A. Schober, S. Dechert, F. Meyer, Eur. J. Inorg. Chem. 2015, 26, 4348-4353.

[56] B. Radaram, J. A. Ivie, W. M. Singh, R. M. Grudzient, J. H. Reibenspies, C. E. Webster, X. Zhao, Inorg. Chem. 2011, 50, 10564-10571.

[57] X. Elias, Q. Liu, C. Gimbert-Suriñach, R. Matheu, P. Mantilla-Perez, A Martinez-Otero, X. Sala, J. Martorell, A. Llobet, ACS Catal. 2016, 6 3310-3316.

[58] N. C. King, C. Dickinson, W. Zhou, D. W. Bruce, Dalton Trans. 2005, 6 , 1027-1032.

[59] M. Roca-Ayats, E. Herreros, G. García, M. A. Peña, M. V. Martínez Huerta, Appl. Catal. B Environ. 2016, 183, 53-60.

[60] E. Demir, S. Akbayrak, A. M. Önal, S. Özkar, J. Colloid Interface Sci. 2019, 534, 704-710.

[61] Y. Zhang, E. C. Judkins, D.R. McMillin, D. Mehta, T. Ren, ACS Catal. 2013, 3, 2474-2478

[62] T. E. Lister, Y. V. Tolmachev, Y. Chu, W. G. Cullen, H. You, R. Yonco, Z. Nagy, J. Electroanal. Chem. 2003, 554/555, 71-76.

[63] L. A. Näslund, A. S. Ingason, S. Holmin, J. Rosen, J. Phys. Chem. 2014, 118, 15315-15323.

[64] J. Cheng, H. Zhang, H. Ma, H. Zhang, Y. Zou, Electrochim. Acta 2010 55, 1855-1861.

[65] Y. Li, L. A. Zhang, Y. Qin, F. Chu, Y. Kong, Y. Tao, Y. Li, Y. Bu, D. Ding M. Liu, ACS Catal. 2018, 8, 5714-5720.

[66] R. Ye, Y. Liu, Z. Peng, T. Wang, A. S. Jalilov, B. I. Yakobson, S. H. Wei, J. M. Tour, ACS Appl. Mater. Interfaces 2017, 9, 3785-3791. 
[67] C. Xu, M. Ming, Q. Wang, C. Yang, G. Fan, Y. Wan, D. Gao, J. Bi, Y. Zhang, J. Mater. Chem. A 2018, 6, 14380-14386.

[68] G. Rahman, S. A. Mian, A. H. A. Shah, O. S. Joo, J. Appl. Electrochem. 2016, 46, 459-468.

[69] R. K. Shervedani, A. Amini, Carbon 2015, 93, 762-773.

[70] Y. Sugawara, K. Kamata, T. Yamaguchi, ACS Appl. Energy Mater. 2019, 2, 956-960

[71] K. Magdić, K. Kvastek, V. Horvat-Radošević, Electrochim. Acta 2015 , 167, 455-469.

[72] C. Amiens, D. Ciuculescu-Pradines, K. Philippot, Coord. Chem. Rev. 2016, 308, 409-432.

[73] S. Drouet, J. Creus, V. Collière, C. Amiens, J. García-Antón, X. Sala, K. Philippot, Chem. Commun. 2017, 53, 11713-11716.

[74] J. Creus, S. Drouet, S. Suriñach, P. Lecante, V. Collière, R. Poteau, K. Philippot, J. García-Antón, X. Sala, ACS Catal. 2018, 8, 11094-11102.

[75] J. Creus, L. Mallón, N. Romero, R. Bofill, A. Moya, J. L. G. Fierro, R. Mas-Ballesté, X. Sala, K. Philippot, J. García-Antón, Eur. J. Inorg. Chem. DOI: 10.1002/ejic.201801438.

[76] Q. Wang, M. Ming, S. Niu, Y. Zhang, G. Fan, J.-S. Hu, Adv. Energy Mater. 2018, 8, 1801698.

[77] X. Cheng, H. Wang, M. Ming, W. Luo, Y. Wang, Y. Yang, Y. Zhang, D. Gao, J. Bi, G. Fan, ACS Sustainable Chem. Eng. 2018, 6, 11487-11492.

[78] H. Wang, C. Xu, Q. Chen, M. Ming, Y. Wang, T. Sun, Y. Zhang, D. Gao, J. Bi, G. Fan, ACS Sustainable Chem. Eng. 2019, 7, 1178-1184.

[79] Q. Song, X. Qiao, L. Liu, Z. Xue, C. Huang, T. Wang, ChemComm 2019, 55, 965-968.

[80] W. Gou, J. Li, W. Gao, Z. Xia, S. Zhang, Y. Ma, ChemCatChem 2019 DOI: $10.1002 /$ cctc. 201900006 .

[81] F. Li, G.-F. Han, H.-J. Noh, I. Ahmad, I.-Y. Jeon, J.-B. Baek, Adv. Mater. 2018, 30, 1803676.

[82] Z. L. Wang, K. Sun, J. Henzie, X. Hao, C. Li, T. Takei, Y. M. Kang, Y. Yamauchi, Angew. Chem. Int. Ed. 2018, 57, 5848-5852.

[83] Z. Chen, J. Lu, Y. Ai, Y. Ji, T. Adschiri, L. Wan, ACS Appl. Mater. Interfaces 2016, 8, 35132-35137.

[84] J. Wang, Z. Wei, S. Mao, H. Li, Y. Wang, Energy Environ. Sci. 2018, 11, 800-806.

[85] X. Zhang, A. Chen, Z. Zhang, M. Jiao, Z. Zhou, J. Mater. Chem. A 2018, 6, 11446-11452

[86] J. Zhang, P. Liu, G. Wang, P. P. Zhang, X. D. Zhuang, M. W. Chen, I. M. Weidinger, X. L. Feng, J. Mater. Chem. A 2017, 5, 25314-25318.

[87] B. Lu, L. Guo, F.Wu, Y. Peng, J. E. Lu, T. J. Smart, N. Wang, Y. Z. Finfrock, D. Morris, P. Zhang, N. Li, P. Gao, Y. Ping, S. Chen, Nat. Commun. 2019, 10, 631.

[88] Y. Zheng, Y. Jiao, Y. Zhu, L. H. Li, Y. Han, M. Jaroniec, S.-Z. Qiao, J. Am. Chem. Soc. 2016, 138, 16174-16181.

[89] K. Gao, Y. Wang, Z. Wang, Z. Zhu, J. Wang, Z. Luo, C. Zhang, X. Huang, H. Zhang, W. Huang, Chem. Commun. 2018, 54, 4613-4616.

[90] D. Luo, B. Zhou, Z. Li, X. Qin, Y. Wen, D. Shi, Q. Lu, M. Yang, H. Zhou, Y. Liu, J. Mater. Chem. A 2018, 6, 2311-2317.

[91] Y. Shi, B. Zhang, Chem. Soc. Rev. 2016, 45, 1529-1541.

[92] J. Q. Chi, W. K. Gao, J. H. Lin, B. Dong, K. L. Yan, J. F. Qin, B. Liu, Y. M. Chai, C. G. Liu, ChemsusChem 2018, 11, 743-752.

[93] Z. Pu, I. S. Amiinu, Z. Kou, W. Li, S. Mu, Angew. Chem. Int. Ed. 2017, 56, 11559-11564.

[94] T. Liu, S. Wang, Q. Zhang, L. Chen, W. Hu, C. M. Li, Chem. Commun. 2018, 54, 3343-3346.

[95] T. Liu, B. Feng, X. Wu, Y. Niu, W. Hu, C. M. Li, ACS Appl. Energy Mater. 2018, 1, 3143-3150.

[96] T. Cheng, L. Wang, B. V. Merinov, W. A. Godard III, J. Am. Chem. Soc. 2018, 140, 7787-7790.

[97] J. Yu, Y. Guo, S. She, S. Miao, M. Ni, W. Zhou, M. Liu, Z. Shao, Adv. Mater. 2018, 30, 1800047.

[98] J. Liu, Y. Zheng, D. Zhu, A. Vasileff, T. Ling, S.-Z. Qiao, Nanoscale 2017, 9, 16616-16621.

[99] P. Jiang, Y. Yang, R. Shi, G. Xia, J. Chen, J. Su, Q. Chen, J. Mater. Chem. A 2017, 5, 5475-5485.

[100] E. Demir, S. Akbayrak, A. M. Önal, S. Özkar, J. Colloid Interface Sci. 2018, 531, 570-577.
[101] U. Joshi, S. Malkhandi, Y. Ren, T. L. Tan, S. Y. Chiam, B. S. Yeo, ACS Appl. Mater. Interfaces 2018, 10, 6354-6360.

[102] L. Zhu, Q. Cai, F. Liao, M. Shengb, B. Wub, M. Shao, Electrochem. Commun. 2015, 52, 29-33.

[103] X. Yang, Z. Zhao, X. Yu, L. Feng, Chem. Commun. DOI: $10.1039 / \mathrm{c} 8 \mathrm{cc} 09993 \mathrm{f}$

[104] Y. Liu, X. Lu, Z. Che, C. Zhang, M. Han, J. Bao, Z. Dai, Chem. Commun. 2018, 54,12202-12205.

[105] E. Demir, S. Akbayrak, A. M. Önal, S. Özkar, ACS Appl. Mater Interfaces 2018, 10, 6299-6308.

[106] J. Su, Y. Yang, G. Xia, J. Chen, P. Jiang, Q. Chen, Nat. Commun. 2017 8, 14969.

[107] Y. Xu, Y. Li, S. Yin, H. Yu, H. Xue, X. Li, H. Wang, L. Wang, Nanotechnology 2018, 29, 225403.

[108] S. Liu, Q. Liu, Y. Lv, B. Chen, Q. Zhou, L. Wang, Q. Zheng, C. Che, C Chen, Chem. Commun. 2017, 53, 13153-13156.

[109] Y. Liu, S. Liu, Y. Wang, Q. Zhang, L. Gu, S. Zhao, D. Xu, Y. Li, J. Bao, Z. Dai, J. Am. Chem. Soc. 2018, 140, 2731-2734.

[110] R. K. Shervedani, M. Torabi, M. S. Foroushani, J. Phys. Chem. C 2018, 122, 17621-17631

[111] Y. Yamada, S. Shikano, S. Fukuzumi, J. Phys. Chem. C 2013, 117, 13143-13152.

[112] Y. Yamada, T. Miyahigashi, H. Kotani, K. Okubo, S. Fukuzumi, J. Am. Chem. Soc. 2011, 133, 16136-16145.

[113] S. Fukuzumi, Y. Yamada, J. Mater. Chem. 2012, 22, 24284-24296.

[114] Y. Yamada, T. Miyahigashi, K. Ohkubo, S. Fukuzumi, Phys. Chem. Chem. Phys. 2012, 14, 10564-10571.

[115] C. Kong, Z. Li, G. Lu, Int. J. Hydrogen Energy 2015, 40, 5824-5830.

[116] Y. Yamada, K. Yano, S. Fukuzumi, Aust. J. Chem. 2012, 65, 15731581

[117] L. Francàs, E. Burns, L. Steier, H. Cha, L. Solà, X. Li, P. Shakya, R. Bofill, J. García-Antón, X. Sala, J. R. Durrant. Chem. Commun. 2018 $54,5732-5735$

[118] M. A. Melo, Jr., Z. Wu, B. A. Nail, A. T. De Denko, A. F. Nogueira, F. E. Osterloh, Nano Lett. 2018, 18, 805-810.

[119] Q. Wang, T. Hisatomi, Q. Jia, H. Tokudome, M. Zhong, C. Wang, Z. Pan, T. Takata, M. Nakabayashi, N. Shibata, Y. Li, I. D. Sharp, A. Kudo, T. Yamada, K. Domen, Nat. Mater. 2016, 15, 611-615. 